\title{
REPENSAR LA PROFUNDIZACIÓN FINANCIERA: ESTABILIDAD Y CRECIMIENTO EN LOS MERCADOS EMERGENTES
}

\author{
Ratna Sabay, Martin Čibák, \\ Papa N'Diaye, Adolfo Barajas y otros*
}

1. Los sistemas financieros de los mercados emergentes (ME) se han profundizado notablemente en las últimas décadas, pero la mayoría está muy por debajo de los niveles de las economias avanzadas (EA). A finales de 2013, el crédito privado pendiente representó en promedio cerca del 50\% del PIB de los ME, mientras que desde 2000 los mercados de valores aumentaron entre el 10\% y el 15\% del PIB y representaron en promedio un 40\% del PIB. Pero estos niveles aún no alcanzan a los de las EA, donde el crédito privado representa en promedio más del 130\% del PIB y la capitalización bursátil es cercana al 70\% del PIB, a

\footnotetext{
* La lista completa de autores incluye además a Ran Bi, Diana Ayala, Yuan Gao, Annette Kyobe, Lam Nguyen, Christian Saborowski, Katsiaryna Svirydzenka y Seyed R. Yousefi. Las opiniones expresadas son de los autores y no representan necesariamente la opinión del FMI, de su Junta Ejecutiva ni de la gerencia del FMI. E1 profesor Ross Levine proporcionó asesoría experta. Los autores reconocen las útiles contribuciones de Thanos Arvanitis y Prachi Mishra en las primeras etapas de este proyecto. Nicolás Arregui, Nicolas Blancher, Luis Brandao-M., Giovanni Dell'Arricia, Johannes Eugster, Erik Feyen, Mark Fisher, Pilar García M., Alexandros Mourmouras, y Sami B. Naceur proporcionaron invaluables insumos. Gracias al personal del Banco Mundial por la compilación de algunos de los datos que se usan en este trabajo. Los autores agradecen a David Lipton, José Viñals, Chang Yong Rhee, Hugh Bredenkamp, Nigel Chalk, Luis Cubeddu, Nathan Porter, Ulric Erickson von Allmen, Martin Sommer, Jehann Jack y muchos otros colegas del FMI por sus comentarios. El proyecto también se benefició de los comentarios recibidos en los seminarios y retroalimentación útil de los directores ejecutivos del FMI y su personal. Artículo original en inglés: "Rethinking financial deepening: Stability and growth in emerging markets", IMF Staff Discussion Note, mayo de 2015, [http://www.imf.org/external/pubs/ft/sdn/2014/ sdn1402.pdf]. Traducción de Alberto Supelano. E1 FMI no se hace responsable por la traducción. Fecha de recepción: 10 de agosto de 2015, fecha de aceptación: 29 de octubre de 2015. Sugerencia de citación: Sahay, R.; M. Čihák, P. N’Diaye, A. Barajas, "Repensar la profundización financiera: estabilidad y crecimiento en los mercados emergentes", Revista de Economía Institucional 17, 33, 2015, pp.73107. DOI: http://dx.doi.org/10.18601/01245996.v17n33.04
} 
pesar del desapalancamiento posterior a la crisis financiera mundial de 2008.

2. La crisis financiera mundial de 2008 suscitó preguntas legitimas acerca de lo que salió mal y si hay lecciones para los ME. ¿Hay límites al desarrollo financiero para el crecimiento y la estabilidad? ¿Hay un ritmo adecuado del desarrollo? ¿La integración financiera ayuda o perjudica a las economías? ¿Cuál es el papel del entorno regulatorio e institucional para que el sistema financiero sea seguro? Algunas de estas preguntas reflejan las preocupaciones de las autoridades de política de los ME que fueron testigo de esta crisis colosal, la cual se originó en las EA, donde el sector financiero se ha vuelto complejo y muy grande. Este escrito aborda cada una de estas preguntas.

3. El desarrollo financiero por lo general aumenta la resiliencia de un país y estimula el crecimiento económico, pero pueden surgir tradeoffs entre crecimiento y estabilidad. Una vasta literatura teórica y empírica muestra que el desarrollo financiero tiene beneficios: moviliza el ahorro, promueve un mayor intercambio de información, mejora la asignación de recursos, y facilita la diversificación y la gestión del riesgo. También promueve la estabilidad financiera en la medida en que sistemas financieros profundos y líquidos con diversos instrumentos ayudan a mejorar la resiliencia de los países a choques que provienen, por ejemplo, de flujos de capital volátiles. Sin embargo, también hay costos, en particular a altos niveles de desarrollo financiero. De hecho, puede haber casos donde hay "demasiadas finanzas" - es decir, casos donde los costos superan a los beneficios del desarrollo financiero. Una de las preguntas que este escrito intenta responder es si los ME ya alcanzaron tales límites.

4. Hay razones adicionales para reexaminar el papel del desarrollo financiero en los ME en esta coyuntura. Los EM hoy enfrentan un doble desafío: un desafío de crecimiento en el contexto de desaceleración del crecimiento potencial y de envejecimiento de la población en muchos ME, y un desafío de estabilidad en un mundo más interconectado y volátil. ¿Cómo puede ayudar el desarrollo financiero a que los ME enfrenten estos desafíos? ¿Cómo pueden los EM cosechar los beneficios del desarrollo financiero al tiempo que limitan los costos? $\mathrm{Y}$ aunque la lista de preguntas puede continuar, una cosa queda clara: es necesario revaluar el alcance del desarrollo financiero.

5. Un aporte de este trabajo es el desarrollo de una medida amplia de desarrollo financiero, llamada indice DF. Desde los años setenta la mayor parte de la literatura empírica lo mide en forma aproximada mediante la relación entre crédito privado y PIB, y en menor medida, 
mediante la capitalización del mercado de valores, también como porcentaje del PIB. El índice que elaboramos para este análisis abarca las instituciones -bancarias y no bancarias- y los mercados, y cubre tres dimensiones: profundidad, acceso y eficiencia.

6. El trabajo tiene cinco principales resultados. Primero, usando el nuevo índice DF, el análisis confirma la relación positiva entre desarrollo financiero y crecimiento. Segundo, los rendimientos marginales para el crecimiento de un mayor desarrollo financiero disminuyen a altos niveles de desarrollo financiero; es decir, hay una relación significativa, en forma de campana, entre desarrollo financiero y crecimiento. Hay una relación no lineal similar para la estabilidad económica. Los efectos del desarrollo financiero sobre el crecimiento y la estabilidad muestran que hay tradeoffs, puesto que en algún momento los costos superan a los beneficios. Sin embargo, la mayoría de los ME aún está en una región favorable donde un mayor desarrollo financiero promueve mayor crecimiento y estabilidad. Curiosamente, el efecto de debilitamiento sobre el crecimiento a altos niveles de desarrollo financiero proviene de la profundización financiera y no del mayor acceso o la mayor eficiencia. Tercero, el ritmo de desarrollo financiero importa. La evidencia muestra que un ritmo demasiado rápido lleva a la inestabilidad. Cuarto, hay un camino para lograr el desarrollo económico que implica muy pocos o ningún tradeoff con la estabilidad financiera, en el que un subconjunto de fuertes principios de regulación y supervisión promueve el crecimiento y la estabilidad. Quinto, no hay “una receta única para todos" en la secuencia de instituciones y mercados, pero, cuando las economías se desarrollan, los beneficios relativos de las instituciones disminuyen y los de los mercados aumentan.

7. El resto del artículo está estructurado como sigue. La próxima sección resume los hallazgos sobre la relación entre desarrollo financiero y crecimiento/estabilidad. Luego se presenta el índice DF y se pasa revista al desarrollo financiero en el universo ME. La sección posterior examina el impacto del desarrollo financiero sobre el crecimiento y la estabilidad, así como los tradeoffs entre ellos. La penúltima sección presenta evidencia de que un entorno propicio puede mejorar el tradeoff. Y la última presenta las implicaciones de política para los ME.

\section{CONTEXTO}

8. Las finanzas y el crecimiento económico (o nivel de ingreso per cápita) tienen una relación de doble sentido. Cuando la actividad real se expande las finanzas crecen en respuesta a la creciente demanda del sector no financiero de servicios financieros. En palabras de Robinson (1952, 
86), “donde la empresa lidera, las finanzas la siguen”. Esta visión de las finanzas está relativamente bien establecida en la literatura. Al mismo tiempo, las finanzas también pueden llevar a un mayor crecimiento.

9. Este trabajo explora los efectos de las finanzas en el crecimiento económico. Muchos autores, al menos desde Bagehot (1873), argumentan que las finanzas facilitan el crecimiento económico. Por ejemplo, McKinnon (1973) y Shaw (1973) señalaron que los impedimentos al desarrollo financiero (como la represión financiera) obstaculizaban el crecimiento limitando la cantidad de ahorros que se podían movilizar con fines de inversión e impidiendo que la intermediación financiera canalizara esos recursos hacia las actividades más productivas. En los años noventa aparecieron nuevos modelos teóricos que formalizaron estas ideas considerando el crecimiento endógeno y las diversas funciones del sistema financiero. Levine (2005) resume los principales canales a través de los cuales se espera que las finanzas influyan en el crecimiento: producción de información, asignación de capital a usos productivos, supervisión de las inversiones y ejercicio del control corporativo, facilitación del comercio, diversificación y manejo del riesgo, movilización y agrupación del ahorro, y facilitación del intercambio de bienes y servicios. Las variables que se usan en la literatura empírica sobre finanzas -como la relación entre crédito privado y PIB, y capitalización de mercado a PIB- son aproximaciones toscas que no necesariamente captan qué tan bien se cumplen esas funciones. Esto se debe tener en cuenta cuando se interpretan los resultados empíricos.

10. Un reto clave es el de establecer empiricamente la causalidad entre finanzas y crecimiento económico. King y Levine (1993) fueron los primeros que abordaron este tema en un contexto de regresión entre países. En su trabajo encontraron que los niveles iniciales de profundidad financiera -aproximados por el tamaño del sistema bancario con respecto al PIB- podían predecir las tasas de crecimiento posteriores durante largos periodos, incluso controlando otras variables explicativas. Más tarde, Levine y Zervos (1998) incorporaron la profundidad del mercado de valores y encontraron que la causalidad iba de las finanzas al crecimiento.

Estos resultados se mantienen cuando el enfoque se refina usando variables instrumentales (Levine et al., 2000). En la pasada década el trabajo empírico se desarrolló con la aplicación de técnicas dinámicas de datos de panel, usando valores rezagados de las variables financieras como instrumentos y controlando otros determinantes del crecimiento (Beck y Levine, 2004). El presente artículo sigue este último 
enfoque, usa variables de control y técnicas econométricas similares para asegurar que la relación no es de simple correlación sino de una causalidad que va de las finanzas al crecimiento.

11. La literatura reciente ha encontrado que el vinculo positivo convencional finanzas-crecimiento se debilita cuando se usan datos posteriores a 1990. Nuevos estudios encuentran que la contribución del desarrollo financiero al crecimiento difiere entre regiones, países y niveles de ingreso (Barajas et al., 2013; Nili y Rastad, 2007; Khan et al., 2001). También se ha identificado que la creciente incidencia de crisis bancarias contribuye a la "desaparición" del vínculo empírico entre finanzas y crecimiento (Rousseau y Wachtel, 2011). Estudios recientes muestran así mismo que hay un punto más allá del cual una profundización adicional puede reducir el crecimiento -el efecto "demasiadas finanzas" (Arcand et al., 2012) - y muestran las no linealidades relacionadas con la profundidad financiera. Aizenman et al., (2015) examinan datos a nivel de sector de 41 economías y también encuentran que las finanzas incrementan el crecimiento, pero solo hasta cierto punto, y que tienen efectos heterogéneos entre sectores ${ }^{1}$.

12. Se han propuesto muchas explicaciones del debilitamiento del nexo finanzas-crecimiento, especialmente a altos niveles de profundidad financiera. Cecchetti y Kharroubi (2015) se centran en los efectos negativos sobre la eficiencia asignativa y sobre el traslado de capital humano del sector real al sector financiero cuando este se expande rápidamente. Un estudio reciente de Dabla et al. (2015) sugiere que, antes de la crisis financiera mundial de 2008, los recursos de las economías avanzadas se estaban desviando hacia el sector financiero desde los sectores más productivos.

De Gregorio y Guidotti (1995) sugieren que los países de altos ingresos pueden haber llegado al punto en que la profundidad financiera ya no contribuye a aumentar la eficiencia de la inversión. Rajan (2005) resalta los peligros del desarrollo financiero que lleva a grandes y complicados sistemas financieros, el cual puede terminar en una "crisis catastrófica". Gennaioli et al. (2012) muestran que en presencia de algún riesgo de cola omitido, la innovación financiera puede aumentar la fragilidad financiera, aun en ausencia de apalancamiento ${ }^{2}$.

\footnotetext{
${ }^{1}$ Además, su estudio presenta evidencia de la necesidad de complementar las medidas convencionales de profundidad -a las que llaman "cantidad de finanzas"con medidas de "calidad", como el margen entre tasas de interés activas y pasivas.

${ }^{2}$ Wolf (2009) señaló que el sector financiero de Estados Unidos creció seis veces más rápidamente que el PIB nominal antes de la crisis financiera de 2008 y argumentó que "en vez de ser un servidor, las finanzas se han convertido en el amo de la economía”.
} 
13. Hay dos puntos de vista opuestos sobre la relación entre finanzas $y$ estabilidad económica. Uno es que el desarrollo financiero relaja la volatilidad reduciendo las fricciones/asimetrías de información, que reduce la sensibilidad de las condiciones de financiación a la variación del patrimonio neto de los prestatarios, lo cual reduce la amplificación de los ciclos que ocurre a través del acelerador financiero (Bernanke et al., 1999). También se dice que el desarrollo financiero promueve el reparto del riesgo, lo que reduce las restricciones financieras, mejora la capacidad de empresas y hogares para absorber choques, y hace posible una mayor suavización del consumo. El punto de vista opuesto es que las finanzas aumentan la volatilidad económica y financiera y la probabilidad de crisis, promoviendo un apalancamiento y una toma de riesgos mayores, sobre todo cuando el sistema financiero está mal regulado y supervisado.

\section{DESARROLLO FINANCIERO ENMERCADOS EMERGENTES ATRA- VÉS DEL LENTE DEL ÍNDICE AMPLIO}

\section{A. MEDICIÓN DEL DESARROLLO FINANCIERO: UN NUEVO ÍNDICE}

14. Los sectores financieros evolucionan y los sistemas financieros modernos se vuelven más multifacéticos con el paso del tiempo. En lo que respecta a las instituciones financieras, los bancos suelen ser las más grandes y más importante, aunque los bancos de inversión, compañías de seguros, fondos de inversión, fondos de pensiones, sociedades de capital riesgo y muchos otros tipos de instituciones financieras no bancarias hoy desempeñan un papel fundamental (ver ejemplos en los recuadros 1 a 3). Así mismo, los mercados financieros han evolucionado de maneras que permiten a individuos y empresas diversificar sus ahorros, y a las empresas recaudar dinero a través de acciones, bonos y mercados de divisas. La constelación de esas entidades y mercados financieros facilita la prestación de servicios financieros. A su vez, la eficiencia y el acceso a estos servicios ayudan a moldear el nivel y la tasa de aumento de la prosperidad económica.

15. La diversidad de sistemas financieros entre países implica que se necesita observar varios indicadores para medir el desarrollo financiero. La gráfica 1 presenta la evolución típica de la proporción entre diferentes mercados financieros y el sistema bancario (tamaño de los depósitos) a diferentes niveles de ingreso per cápita, usando datos de 128 países entre 1980 y 2013. La gráfica muestra que, en relación con el sistema bancario, los mercados nacionales de bonos privados y los mercados de valores se hacen más grandes cuando el PIB per cápita aumenta (el 
área sombreada). Los fondos de inversión y los fondos de pensiones empiezan a crecer rápidamente a niveles de ingreso más altos, mientras que el tamaño relativo de los mercados de bonos públicos tiende a disminuir. Por tanto, confiar únicamente en medidas individuales centradas en los bancos puede ser engañoso. En particular, los excesos financieros de la década de 2000 en Estados Unidos no podían ser capturados midiendo simplemente el crédito bancario al sector privado (como porcentaje del PIB), el cual ha sido bastante estable desde 1980, mientras que los activos de las entidades no bancarias se han más que duplicado (gráfica 2). Del mismo modo, aunque Corea y Vietnam tienen niveles similares de profundidad -una relación de crédito privado a PIB cercana al 100\%- el uso de cuentas bancarias es prácticamente universal en Corea, pero en Vietnam solo una cuarta parte de los adultos tiene una cuenta bancaria. Además, una característica importante de los sistemas financieros es su eficiencia: aun si son grandes y tienen amplio alcance, su contribución al desarrollo económico se limitaría si fueran derrochadores e ineficientes ${ }^{3}$.

\section{Gráfica 1}

Desarrollo del mercado de capitales

Cuando las economías crecen, los mercados no bancarios y los financieros privados aumentan de tamaño con respecto al sistema bancario.

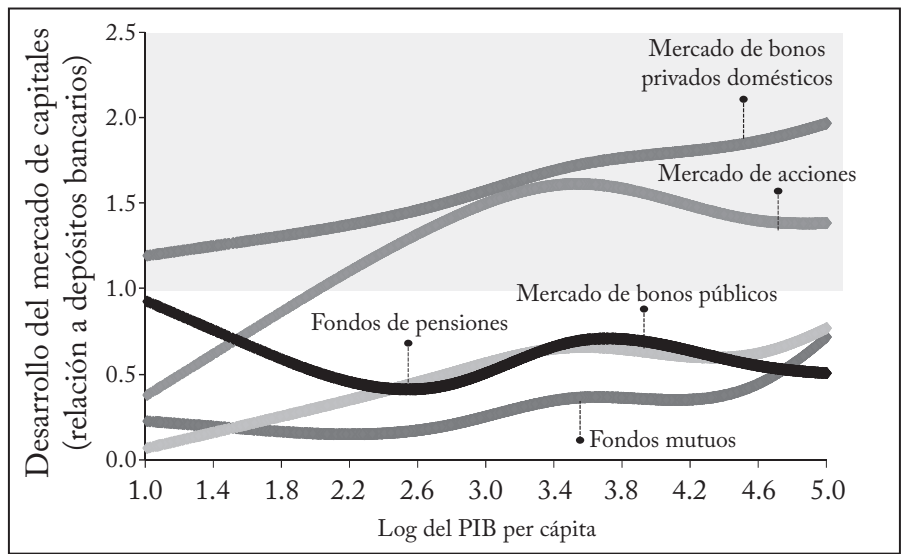

Nota: basada en datos de 128 países entre 1980 y 2013. Las líneas se derivan de una regresión spline cúbica de 5 nudos de los indicadores respectivos (divididos por los depósitos bancarios) contra el PIB per cápita, controlando determinantes de la estructura financiera de cada país como el origen legal y las variables demográficas.

Fuente: estimaciones del personal del FMI.

${ }^{3}$ Este punto también se plantea en Čihák et al. (2012) y Aizenman et al. (2015). 
Gráfica 2

El crédito bancario puede ser una medida engañosa de profundidad y acceso financieros

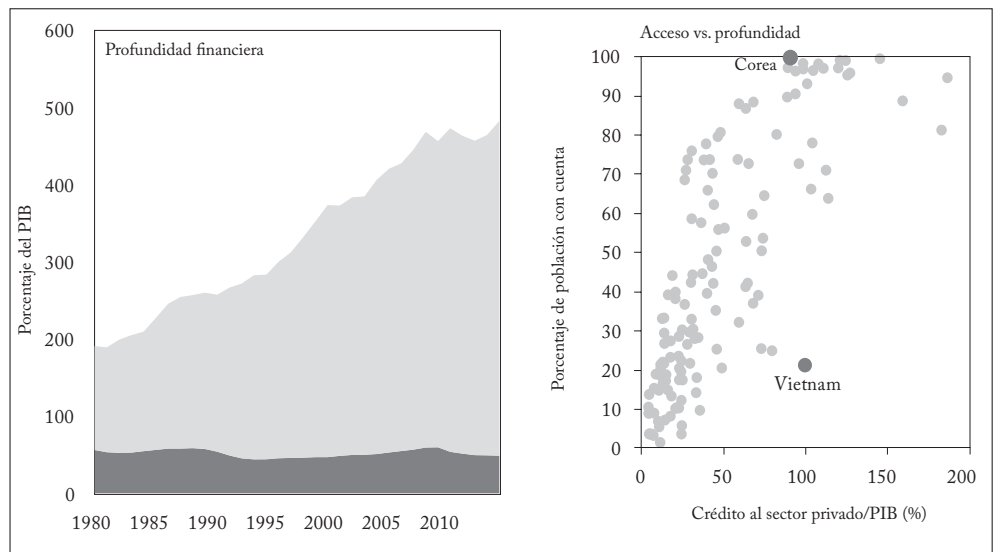

Nota: en el panel izquierdo, el área gris oscuro es el crédito al sector privado con respecto al PIB. E1 área gris es el tamaño de la banca en la sombra con respecto al PIB. En el panel derecho, el eje vertical es el porcentaje de adultos con al menos una cuenta en una entidad financiera a finales de 2011.

Fuente: Global Financial Development Database, Global Findex y estimaciones del personal del FMI.

16. Para superar las deficiencias de los indicadores individuales como proxies del desarrollo financiero se construyó un nuevo indice integral, que capta las instituciones financieras (IF) y los mercados financieros (MF). Las instituciones financieras incluyen bancos, compañías de seguros, fondos de inversión, fondos de pensiones y otros tipos de instituciones financieras no bancarias. Los mercados financieros incluyen principalmente los mercados de acciones y bonos. Dentro de las IF y los MF, se midieron diferentes dimensiones del sistema financiero: profundidad, acceso y eficiencia (gráfica 3). Como muestra el Anexo 1 , aunque el crédito del sistema bancario al sector privado sigue siendo un componente importante del desarrollo financiero, tiene un peso de 0,25 en el subcomponente de profundidad de las IF, el cual tiene a su vez un peso de menos de 0.40 en el subcomponente de las IF. En otras palabras, el crédito bancario aun cumple un papel importante, el cual refleja el papel de los bancos en muchos sistemas financieros, pero está lejos de ser la única causa de los resultados. Para este ejercicio se recogieron datos de 176 países ( $25 \mathrm{EA}, 85 \mathrm{ME}$ y 66 países en desarrollo de bajos ingresos, o PEDBI) para 1980 a 2013.

17. El indice DF se construyó siguiendo la práctica usual en la literatura, como sigue 4 .

- Se elige una lista de indicadores para medir cada subíndice en la parte inferior de la pirámide de la gráfica 3, es decir, IFP, IFA, IFE,

${ }^{4}$ Para más detalles, ver el Anexo 1. 
Gráfica 3

Índice de desarrollo financiero

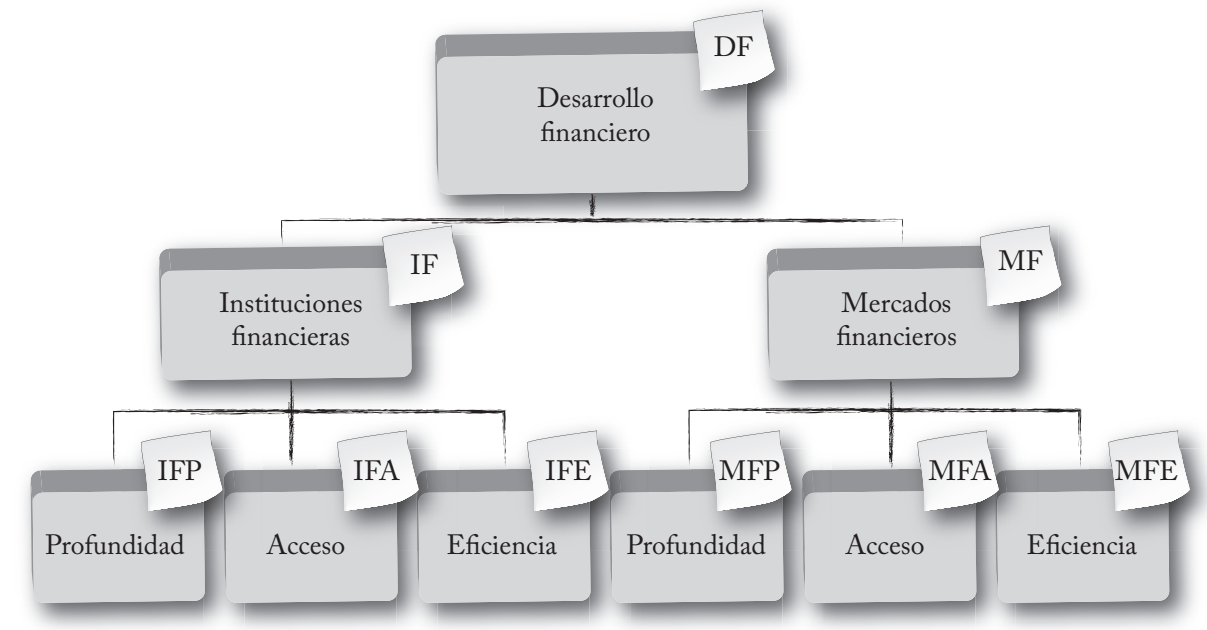

Fuente: personal del FMI, con base en Čihák et al. (2012).

MFP, MFA y MFE, donde las letras P, A y E denotan profundidad, acceso y eficiencia, respectivamente, e I y M instituciones y mercados, respectivamente.

- Cada indicador se normaliza entre 0 y 1 . Así, el valor más alto (más bajo) de una variable dada en el tiempo y entre países es igual a 1 (0) y los demás valores se miden con respecto a estos valores máximos (mínimos). Para evitar errores provenientes de observaciones extremas, los datos se recortan usando los percentiles 5 y 95 como niveles de corte. Los indicadores se definen de modo que los valores más altos indican mayor desarrollo financiero.

- Los indicadores luego se agregan a los seis subíndices de la parte inferior de la pirámide. La agregación es un promedio ponderado de las series subyacentes, donde las ponderaciones se obtienen a partir del análisis de componentes principales y reflejan la contribución de cada serie subyacente a la variación del subíndice específico.

-Por último, los subíndices se agregan en índices de nivel superior utilizando el mismo procedimiento anterior y se culmina en el nivel más agregado: en el índice DF.

18. Si bien hubo desafíos en la construcción de este indice, es un paso importante para medir el desarrollo financiero de modo más completo que antes. Un reto para la literatura empírica es que las medidas amplias solo captan parcialmente las diversas funciones de las finanzas, como su capacidad para facilitar el manejo de riesgos, ejercer el control cor- 
porativo, agrupar el ahorro y otros (Levine, 2005). Este escrito enfrenta el reto de basarse en un conjunto amplio de indicadores, pero sigue siendo un asunto que se debe tener en cuenta cuando se interpretan los resultados empíricos. Otro reto práctico era cómo enfrentar los datos faltantes. La estrategia que se adoptó aquí fue equilibrar la amplitud del índice DF con una cobertura adecuada de países y periodos, $\mathrm{y}$, al mismo tiempo, evitar saltos del índice no relacionados con cambios reales en el desarrollo financiero sino con la adición de nuevas series de datos. En el Anexo 1 se muestra cómo se hizo ${ }^{5}$. El segundo reto es que no se podían encontrar datos de países y periodos suficientemente amplios sobre algunas instituciones y actividades. Un ejemplo es el de los bancos en la sombra, cuya importancia ha aumentado en varios ME, con los riesgos asociados (para un análisis reciente de este tema en una muestra más pequeña de países, ver FMI, 2014a). Por último, diferentes formas de pagos financieros, como transferencias de crédito, deudas directas y banca móvil, son aspectos relevantes de la profundidad y el acceso en muchos países, pero sus indicadores no están disponibles para incluirlos en el índice DF. Ante esos retos y limitaciones de datos, el personal del FMI seguirá mejorando el índice cuando se amplíe la cobertura de datos y se desarrollen métodos de agregación más avanzados ${ }^{6}$.

\section{B. Panorama del DesarRollo FinANCIERo EN LOS ME}

\section{La evolución del índice DF en el periodo de la muestra (1980-2013)} muestra un patrón que confirma lo esperado (gráfica 4). En general, el desarrollo financiero ha progresado notablemente en las EA y en los ME, y en menor medida en los PEDBI. Pero, como era de esperar, la brecha entre los dos primeros grupos se amplió significativamente entre mediados de la década de los noventa y comienzos de la siguiente, lo que refleja ante todo el rápido crecimiento de los sistemas financieros de la EA. Este episodio marca la "era Greenspan" en Estados Unidos, un periodo en que la banca transfronteriza europea se amplió nota-

\footnotetext{
${ }^{5}$ Como se explica en el Anexo 1, los valores faltantes de algunos indicadores en años anteriores se "llenaron hacia atrás" usando las tasas de crecimiento de otros indicadores disponibles. No obstante, para cada subcomponente del DF hay al menos un indicador con observaciones para todo el periodo de la muestra.

6 También debido a limitaciones de datos, en el índice no se incluyeron otras características potencialmente relevantes del desarrollo financiero, como los diversos tipos de intermediarios financieros, la complejidad organizativa de las instituciones y la complejidad de los instrumentos. Se incluyó la combinación deuda versus financiación de capital, cuando ambos tipos fueron capturados en el índice, mientras que algunos de los análisis empíricos de apoyo probaron si la combinación deuda-capital, para un nivel dado de DF, alteraba la relación finanzas-crecimiento.
} 
blemente, igual que la banca de inversión y la banca por Internet ${ }^{7}$. Por otro lado, en este período el desarrollo financiero fue más moderado en los ME y se estancó relativamente en los PEDBI. La brecha de desarrollo financiero entre las EA y los ME se redujo después de la crisis financiera mundial, como reflejo del desapalancamiento en las EA.

Gráfica 4

Desarrollo financiero a través del tiempo

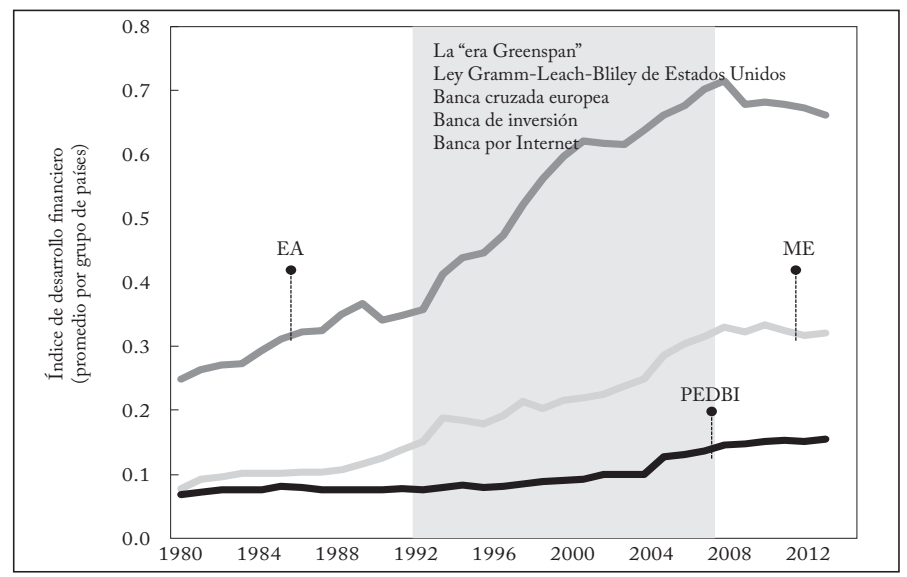

Fuente: estimaciones del personal del FMI.

20. Una comparación instantánea entre grupos de pares da una imagen muy diferente (gráfica 5). En particular, la "brecha" de desarrollo financiero entre EA y ME difiere en las distintas dimensiones del desarrollo financiero destacadas en la gráfica. Por ejemplo, los ME están más cerca de las EA en instituciones financieras que en mercados financieros. Además, a pesar de la menor profundidad, la eficiencia de las instituciones financieras de los ME y los PEDBI es relativamente alta. Por último, el acceso es bajo, en promedio, en todos los grupos de ingresos, de modo que esta es un área de mejora potencial ${ }^{8}$.

21. Si se observa cada país, hay una variación en el desarrollo financiero dentro del mismo grupo de ingresos (gráfica 6). Algunos ME grandes, como Brasil y China, tienen mayores niveles de desarrollo financiero

${ }^{7}$ La gráfica 4 muestra promedios simples entre países y así el peso de Estados Unidos es relativamente pequeño. Además, el índice no capta préstamos transfronterizos directos porque se centra en aspectos internos del desarrollo financiero.

${ }^{8}$ Aunque todos los índices son medidas relativas -cada observación de una variable dada en un país se mide con respecto al nivel máximo observado-, el nivel inferior del subcomponente de acceso promedio implica que hay algunos países que alcanzan un alto nivel de acceso, pero la mayoría está más lejos de ese nivel de lo que está de un alto nivel similar en las otras dos dimensiones del DF: profundidad y eficiencia. 


\section{Gráfica 5}

Índice de desarrollo financiero: promedio de grupos de pares

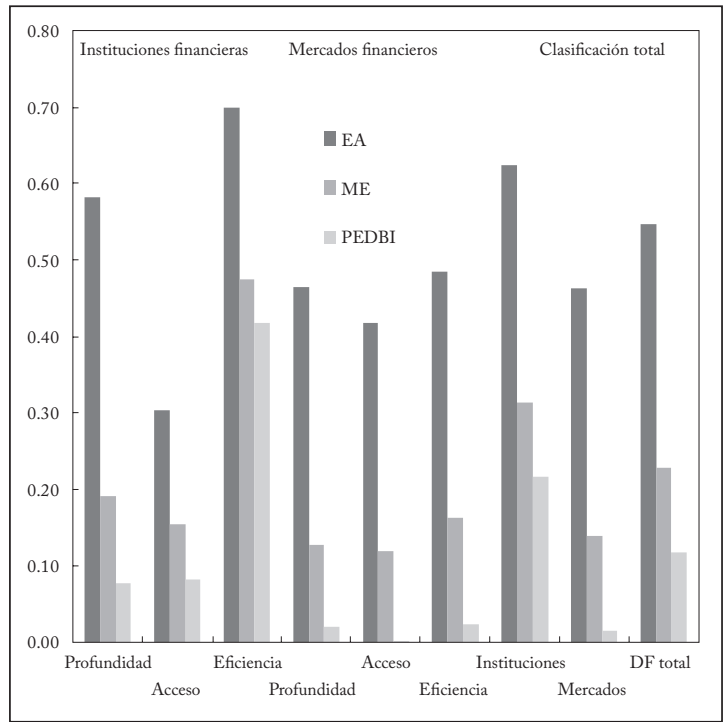

Fuente: estimaciones del personal del FMI.

Gráfica 6

Índice de desarrollo financiero: países seleccionados

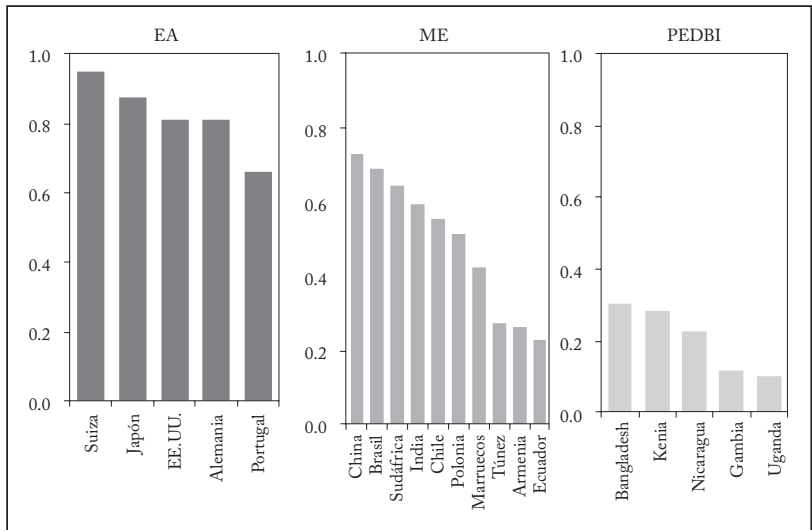

Fuente: estimaciones del personal del FMI.

que algunas EA, como Grecia y Portugal. Y varios ME (como Armenia, Ecuador y Túnez) tienen menores niveles de desarrollo financiero que algunos PEDBI. 


\section{REVALUACIÓN DE LOS BENEFICIOS Y RIESGOS DEL DESARRO- LLO FINANCIERO: ¿HAY UN TRADEOFF ENTRE CRECIMIENTOY ESTABILIDAD?}

\section{A. DESARROLLO FINANCIERO Y CRECIMIENTO}

22. El análisis empirico indica que hay una relación significativa, en forma de campana, entre desarrollo financiero y crecimiento (gráfica 7). E1 método de estimación utilizado para obtener esta relación, que se discute en el Anexo 2, aborda el problema de la endogeneidad y los controles de los episodios de crisis, así como otros determinantes comunes del crecimiento, como el ingreso per cápita inicial, la educación, la apertura comercial, los flujos de inversión extranjera directa, la inflación y el consumo del gobierno9 ${ }^{9}$ Con base en una muestra de 128 países de 1980 a 2013, el análisis sugiere que el desarrollo financiero aumenta el crecimiento, pero los efectos se debilitan a niveles más altos de desarrollo económico, y luego llegan a ser negativos. Esta relación confirma los resultados recientes de la literatura (Arcand et al., 2012).

23. El nivel de desarrollo financiero por encima del cual los efectos positivos sobre el crecimiento empiezan a disminuir está entre 0,4 y 0,7 en el índice DF (gráfica 7). Esta estimación es un promedio de todos los países, incluidos EA, ME y PEDBI, durante 30 años. La gráfica 7 muestra dónde se encuentra un conjunto de países en diferentes etapas de desarrollo financiero en la curva estimada. Cabe destacar que hay una banda amplia alrededor del “punto de inflexión”, la cual refleja la variación de los fundamentales y los entornos institucionales de los países. Con un nivel de confianza del 95\%, el punto donde el impacto marginal de las finanzas sobre el crecimiento se vuelve significativamente negativo es de alrededor de 0,7.

24. Conceptualmente, hay varios canales a través de los cuales niveles muy altos de finanzas pueden tener un efecto negativo sobre el crecimiento (Eugster, 2014; Arcand et al., 2012; Philippon y Reshef, 2012 y 2013). Un argumento es que demasiadas finanzas aumentan la frecuencia de las alzas y bajas y en últimas dejan a los países en peor situación y con un menor crecimiento del PIB real. Otro argumento es que demasiadas finanzas desvían el talento y el capital humano de los sectores productivos al sector financiero. Algunos también argumentan que un sector financiero muy grande puede ser muy susceptible de riesgo moral o extraer rentas de otros sectores, lo cual llevaría a una mala asignación de recursos.

\footnotetext{
${ }^{9}$ Para más detalles sobre los datos, la especificación y el método de estimación, ver el cuadro 1 del Anexo 2.
} 
25. No hay un punto particular de "demasiadas finanzas" para todos los paises y en todo momento. La forma y la ubicación de la campana pueden diferir entre países dependiendo de sus características, incluido el nivel de ingresos, las instituciones y la calidad de la regulación y la supervisión. En otras palabras, un país a la derecha del promedio de "demasiadas finanzas" aún puede estar en su óptimo si la calidad de sus regulaciones y su supervisión es superior al promedio; en cambio, un país a la izquierda del grupo con instituciones débiles puede ya haber alcanzado su máximo. En términos generales, la relación estimada sugiere que un índice DF de 0,45 a 0,7 (con el 95\% de probabilidad) puede generar los mayores rendimientos crecimiento acumulativo (es decir, pasar de 0 al punto de máximo crecimiento) en el intervalo de 4-5 puntos porcentuales, manteniendo constantes otros determinantes del crecimiento.

\section{Gráfica 7}

Efecto del desarrollo financiero sobre el crecimiento

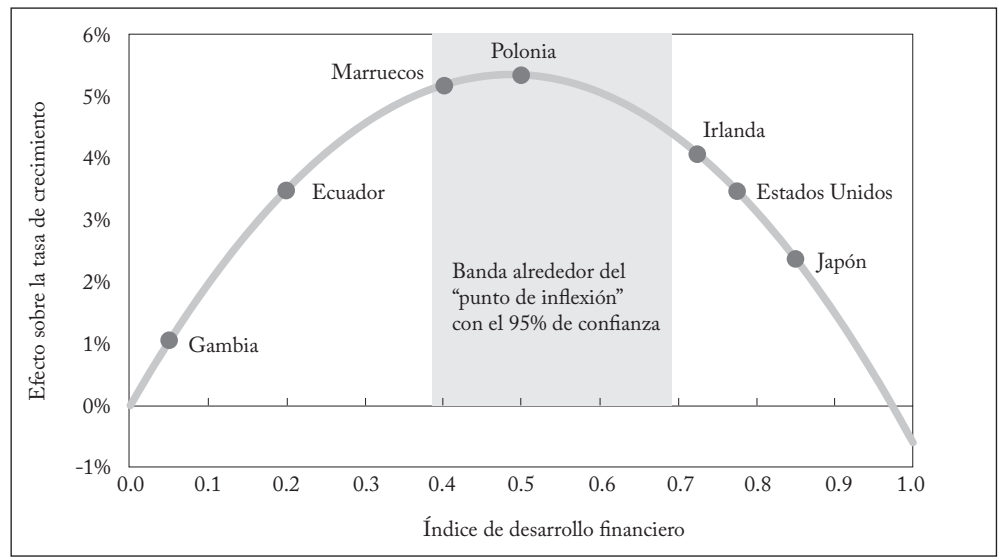

Fuente: estimaciones del personal del FMI.

26. A diferencia de la literatura anterior, la relación estimada es lo suficientemente general para captar el vinculo entre crecimiento y desarrollo financiero de paises en diversas etapas de desarrollo. De hecho, el análisis empírico sugiere que no hay efectos "específicos de los ME" y ninguna variación significativa en la relación entre crecimiento y desarrollo económico entre niveles de ingreso. Esto está en abierto contraste con los resultados de regresiones similares de trabajos anteriores que usan medidas más estrechas de desarrollo financiero, como el crédito privado respecto del PIB. Este debilitamiento de la heterogeneidad observable en la relación finanzas-crecimiento cuando se usa el índice DF sugiere 
que es en general una mejor medida del desarrollo financiero pues capta con mayor precisión las diferencias relevantes entre países.

Gráfica 8

Efecto del desarrollo financiero sobre la acumulación de capital y la PTF

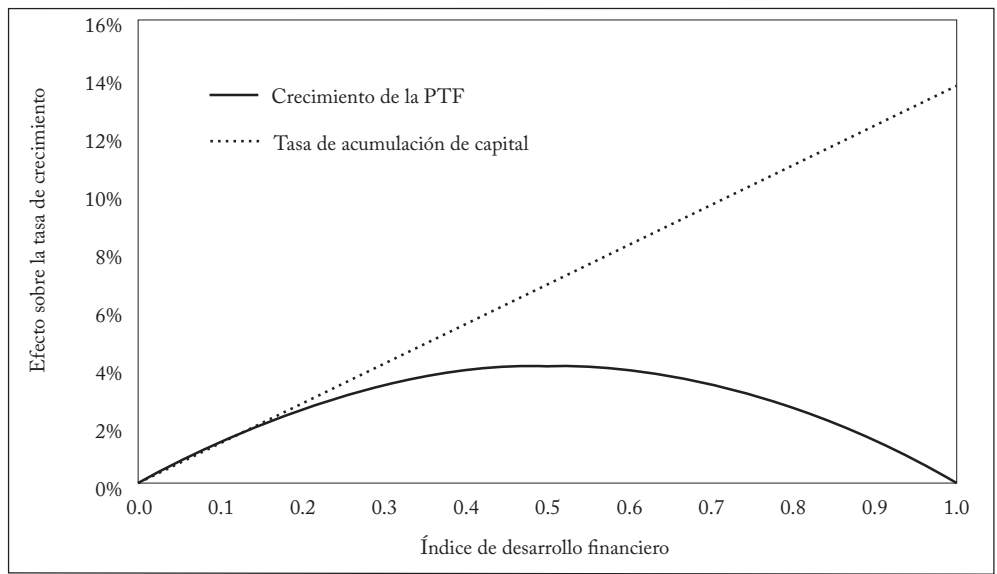

Nota: PTF $=$ productividad total de los factores.

Fuente: estimaciones del personal del FMI.

27. Si se observan los dos componentes del crecimiento -la productividad total de los factores (PTF) y la acumulación de capital- la evidencia empírica sugiere que el efecto "demasiadas finanzas" refleja principalmente el impacto del desarrollo financiero sobre el crecimiento de la PTF (gráfica 8). Los resultados indican que altos niveles de desarrollo económico no impiden la acumulación de capital sino que llevan a una pérdida de eficiencia de la inversión, lo cual sugiere que la calidad de las finanzas -p. ej., la asignación de recursos financieros a actividades productivas y de capital humano entre sectores- se deteriora a altos niveles de desarrollo financiero. En otras palabras, muchas funciones del sector financiero, como la movilización del ahorro y la facilitación de transacciones, pueden mantenerse intactas a altos niveles de desarrollo financiero, pero otras, como la eficiencia en la asignación de capital y la eficacia del control corporativo, pueden empezar a fallar. De nuevo, las estimaciones no evidencian un efecto específico de los ME en este ejercicio de descomposición.

28. Analizando el efecto de los subindices del indice DF, el debilitamiento del crecimiento a niveles más altos de desarrollo financiero se puede atribuir a la profundización financiera y no a un mayor acceso o a una mayor eficiencia. La relación en forma de campana entre el crecimiento y el índice DF solo se refiere a los componentes de profundidad del índice, 
para los mercados y para las instituciones. Específicamente, el acceso tiene una relación lineal positiva con el crecimiento, mientras que la eficiencia en sí misma no tiene una asociación positiva robusta con el crecimiento de largo plazo. Esto implica que los países que ya hayan alcanzado los máximos beneficios en términos de crecimiento derivados de la profundización de las instituciones y los mercados financieros aún pueden obtener beneficios de crecimiento derivados de un mejor acceso. Por ejemplo, Chile es un país con un índice DF superior al promedio, con instituciones financieras profundas y eficientes, pero puede beneficiarse de un mayor acceso a instituciones y mercados (recuadro 1). El índice DF de Marruecos es similar al promedio de los ME, y tiene espacio para el desarrollo de mercados e instituciones (recuadro 2). El índice DF de Malasia es casi el doble del promedio de los ME, lo que refleja un gran aumento de la profundidad desde la crisis asiática, pero sus instituciones financieras están rezagadas con respecto a las de otros mercados emergentes en acceso (recuadro 3).

\section{RECUADRO 1 \\ DESARROLlo FINANCIERO EN CHILE*}

El desarrollo financiero de Chile se inició seriamente en 1974, cuando una rápida liberalización financiera puso fin a décadas de represión financiera. Entre $1974 \mathrm{y}$ 1976, el gobierno chileno eliminó la mayoría de las regulaciones del sector bancario, incluidas las tasas de interés y los controles de crédito, y privatizó los bancos estatales. La desregulación financiera continuó con reformas al mercado de capitales, seguidas por la liberalización del mercado de seguros, la creación de un sistema de pensiones por capitalización y medidas para facilitar la emisión de bonos. El proceso fue interrumpido por la crisis bancaria de 1982 a 1984, que llevó a una masiva intervención del gobierno en el sector bancario y al restablecimiento de los controles financieros. Pero las reformas financieras se reanudaron poco después de la crisis, y llevaron a una impresionante ampliación del mercado de capitales y a la creación de un gran conjunto de inversionistas institucionales de largo plazo.

Factores especiales contribuyeron a la secuencia de desarrollo del mercado financiero. La creación de un sistema de pensiones por capitalización contribuyó al desarrollo temprano de una base de inversionistas institucionales locales, mientras que la crisis bancaria de comienzos de los ochenta probablemente aceleró el crecimiento de los mercados de acciones y bonos corporativos. La creación de un mercado de bonos soberanos también facilitó desde el principio el desarrollo de otros mercados. La mejora en el cumplimiento de los contratos, la creación de instituciones que redujeron las asimetrías de información y la mayor disponibilidad de garantías ayudaron a profundizar los mercados. E1 crédito bancario total al sector privado hoy se sitúa en el $75 \%$ del PIB, por debajo del promedio de la OCDE, pero muy por encima del promedio de América Latina. Además, la eficiencia de los bancos chilenos, medida por 
el margen de tasas préstamodepósito, está cerca del promedio de la OCDE.

Los mercados de capital son bastante grandes, pero no muy líquidos (cuadro del texto). El mercado de bonos domésticos (excluidos títulos del gobierno) representa casi el 40\% del PIB. E1 mercado no es muy líquido y está dominado por bonos de largo plazo vinculados a la inflación. La baja liquidez, la larga madurez y la indexación a la inflación son el resultado de la

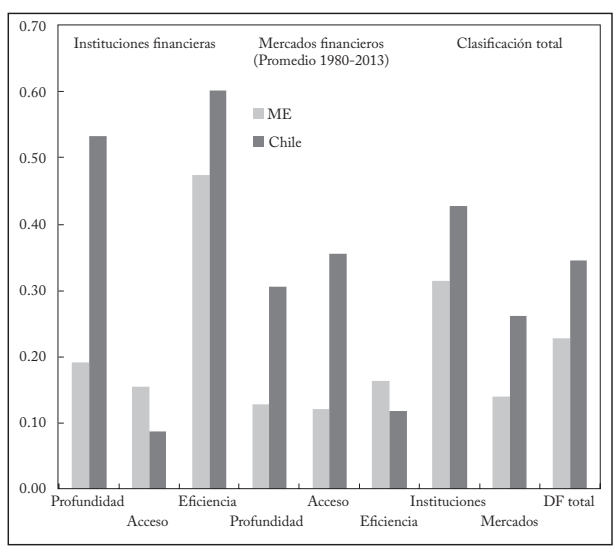
alta demanda de los inversionistas institucionales, en especial de las compañías de seguros de vida que por lo común tienen obligaciones de largo plazo ligadas a la inflación. Chile también tiene un mercado de acciones relativamente grande (el valor de mercado de las compañías cotizadas es cercano al 90\% del PIB) y supera de lejos al de sus vecinos. Pero el mercado de valores chileno es aún relativamente ilíquido, con una rotación baja y decreciente.

Los inversionistas institucionales juegan un papel importante en el sector financiero de Chile. Los fondos de pensiones, las compañías de seguros y los administradores de activos (fondos de inversión) representan casi la mitad de los activos del sector financiero. La presencia de estos inversionistas ha contribuido al fuerte desarrollo del mercado de capitales local, pero puede haber limitado su liquidez debido a las estrategias de comprar y mantener que suelen emplear. Sin embargo, hay evidencia de que la presencia de inversionistas estables como los fondos de pensiones y las compañías de seguros ofrece cierta protección a los sistemas financieros locales contra choques financieros globales.

Aunque Chile ha hecho grandes avances en términos de profundidad de los mercados financieros, siguen existiendo retos de acceso del mercado. Solo el 45\% de los adultos tiene una cuenta bancaria formal (casi la mitad del promedio de la OCDE). Además, la baja liquidez relativa de los mercados de acciones y bonos corporativos limita la capacidad de las empresas más pequeñas para conseguir capital fuera del sistema bancario.

Elaborado por Nicolás Arregui y Luis Brandao-M., tomado en parte de Gallego y Loayza (2000), de la Torre et al. (2012), FMI (2014b) y Banco Mundial (2014).

\section{RECUADRO 2 \\ Profundización FinANCIERA EN MARruecos*}

Marruecos ha hecho sustanciales reformas financieras en las últimas tres décadas, como parte de la agenda para promover el crecimiento y la estabilidad financiera. En los años setenta y ochenta el sector público cubrió gran parte de la inversión, absorbiendo altos niveles de ahorro doméstico, mientras que la inversión 
privada siguió siendo modesta. Las reformas inicialmente se dirigieron al sistema bancario y la política monetaria, en paralelo con el paso a una financiación del presupuesto más basada en el mercado. Estas reformas fueron seguidas por esfuerzos para profundizar los mercados financieros mediante la introducción de nuevos instrumentos y la reforma del mercado de valores. Como la liberalización y la desregulación de las actividades financieras permitieron que los participantes

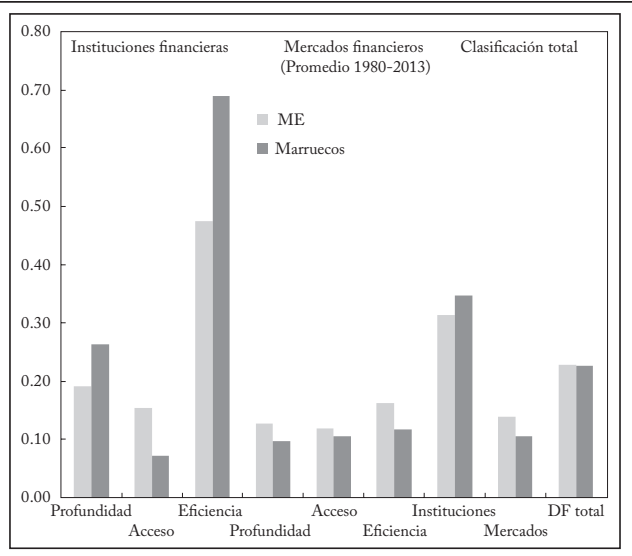
en el mercado asumieran mayores riesgos, se fortalecieron las regulaciones prudenciales y la supervisión bancaria. Las reformas tuvieron un impacto significativo en la intermediación financiera y la estructura del sector financiero, pero aún se necesita más para fortalecer la supervisión financiera y desarrollar el mercado de valores (gráfica del texto).

El sector bancario predomina. Este ha crecido y los activos bancarios equivalían al 126\% del PIB en 2013. E1 sector consta de 19 bancos, incluidos 5 de propiedad mayoritariamente pública y 5 de propiedad mayoritariamente extranjera, y está dominado por 5 bancos que poseen el $80 \%$ de los activos bancarios totales. La profundidad del sistema bancario marroquí está por delante de sus pares del Medio Oriente (con un crédito privado y unos depósitos domésticos del 70\% y el 89\% del PIB, respectivamente). Los bancos tienen redes de sucursales relativamente bien desarrollado en el país; no obstante, solo el 60\% de la población tenía cuenta bancaria en 2013. Además, el acceso a la financiación es difícil para algunos grupos vulnerables y para las pequeñas y medianas empresas (Pymes).

Hay espacio para el desarrollo del sector financiero no bancario. Los mercados de deuda doméstica se caracterizan por una estructura de larga madurez y baja liquidez en el mercado secundario. A pesar de la considerable emisión de deuda titularizada por el gobierno, el mercado de deuda pública está restringido por el cumplimiento parcial del calendario de subastas preanunciadas y las limitadas tenencias extranjeras. La limitada infraestructura de los mercados de deuda pública también afecta al mercado de deuda privada, con grandes rezagos respecto de los indicadores globales para una economía de este tamaño. El valor de las empresas en el mercado de valores es cercano al 50\% del PIB, pero el tamaño del mercado oculta el bajo porcentaje de acciones cotizadas públicamente y las bajas tasas de rotación. Las instituciones financieras no bancarias (fondos mutuos, fondos de pensiones y compañías de seguros) representan casi el $40 \%$ de los activos del sector financiero. E1 total de activos y de primas del sistema de seguros representa el $20 \%$ y el $3 \%$ del $\mathrm{PIB}$, respectivamente. Los fondos mutuos mantienen un $80 \%$ de los activos en títulos de renta fija, y solo un $8 \%$ en valores cotizados. Las compañías de seguros y los fondos de pensiones dominan los activos de los fondos mutuos 
con el $45 \%$ de los activos netos. E1 sistema de pensiones de Marruecos es grande pero dominado por el sector público y es necesario reformarlo para garantizar su viabilidad y ampliar su cobertura. El mercado de valores ha limitado el volumen de negociaciones y el mercado de renta privada fija está poco desarrollado. La continuación del desarrollo de los sistemas de seguros y de pensiones puede ayudar a ampliar la base de inversionistas y mejorar la profundidad y la amplitud del mercado de capitales (FMI, 2014c).

La falta de acceso a la financiación sigue siendo una gran restricción. Por ejemplo, solo el 13\% de las empresas recurren a los bancos para financiar la inversión (cerca de la mitad del promedio mundial). Reconociendo esta limitación, en 2012 y 2014, el Banco Al-Maghrib estableció mecanismos de financiación especiales a favor de las Pymes. El desarrollo de las microfinanzas y las finanzas islámicas, con un énfasis en el mejoramiento de la infraestructura financiera, puede ayudar a avanzar en la agenda de inclusión financiera.

* Elaborado por Pilar García M., Mark Fisher, Sami B. Naceur y Allan G. Auclair.

\section{RECUADRO 3 \\ Profundización FinANCIERA EN MALASIA*}

El sector financiero de Malasia es de gran tamaño, sólido, diversificado y rentable. La profundidad financiera de Malasia (400\% del PIB) apoya la estabilidad macroeconómica y aumenta la resiliencia ayudando a absorber choques externos de términos de intercambio y de cuenta de capital. También reduce el costo de los fondos, y alienta así la inversión pública y privada, incluso en infraestructura, y apoya el crecimiento económico.

El sector financiero de Mala-

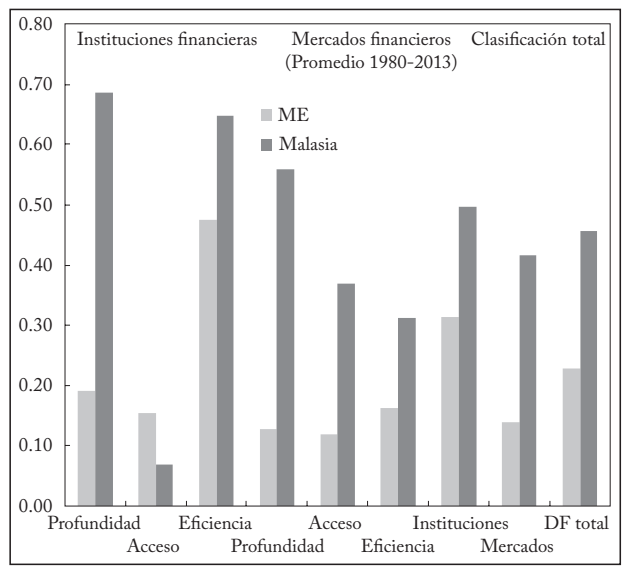
sia incluye bancos convencionales

y bancos islámicos e instituciones financieras no bancarias. Los bancos siguen dominando (con cerca del 50\% de los activos financieros), pero el sector no bancario ha crecido notablemente (gráfica del texto). El sistema bancario es grande, con activos de un 200\% del PIB (un 20\% de los cuales en manos de bancos islámicos), y es concentrado ( 5 grupos bancarios abarcan el $70 \%$ de los activos). Los activos de las instituciones financieras no bancarias (incluidas las instituciones financieras de desarrollo, las compañías de seguros y los intermediarios del mercado de capitales) crecieron del 45\% al 60\% del PIB entre 2009 y 2013. El fondo de previsión de empleados públicos (FPE) es un inversionista institucional clave, con activos de un 60\% del PIB.

Los cambios en el sistema financiero de Malasia reflejan un esfuerzo concertado de varios años del Banco Central de Malasia (BNM) y la Comisión de Valores de 
Malasia (SC). La crisis financiera de 1997 reveló debilidades, incluida la dependencia excesiva del crédito bancario y un sistema bancario fragmentado dominado por instituciones pequeñas y débiles. En respuesta, el BNM se empeñó en construir un sistema financiero estable y sólido consolidando los grupos bancarios y permitiendo la entrada extranjera para mejorar la competencia. E1 BNM y la SC realizan la vigilancia sistémica por medio de un Comité de Estabilidad Financiera conjunto de alto nivel.

El desarrollo de mercados profundos y líquidos de acciones y bonos en moneda nacional es un sello distintivo de la profundización financiera en Malasia y ayuda a proteger la economía contra choques externos. El mercado de bonos se duplicó en los últimos 10 años y no hay una participación extranjera significativa. Cerca del $40 \%$ de los bonos son emitidos por el sector privado (incluidas empresas vinculadas al gobierno). Mientras que el FPE y las compañías de seguros invierten la mayor parte de sus portafolios en el mercado de bonos domésticos, la proporción de activos invertidos en el exterior ha aumentado, lo que refleja la liberalización gradual de las restricciones de portafolio a los residentes. Los inversionistas locales adinerados tienden a comprar grandes cantidades de acciones y bonos domésticos en periodos turbulentos de volatilidad de los flujos de capital, porque la venta de inversionistas extranjeros significa oportunidades de beneficio. Los mercados financieros profundos también han permitido que Malasia se endeude en su propia moneda para invertir en infraestructura (FMI, 2014e).

A pesar de los sólidos balances de los bancos, el riesgo financiero está aumentando después de años de rápido crecimiento del crédito, de tasas reales de interés bajas o negativas sobre los depósitos y de fuerte aumento del apalancamiento. La deuda de los hogares ha aumentado rápidamente. La deuda del sector empresarial también ha aumentado y hoy está cerca del promedio de Asia. Los bancos siguen expandiéndose en el extranjero, pero sus operaciones en el extranjero se financian en gran parte con depósitos en moneda local, lo que limita los riesgos potenciales de financiación y de tasa de cambio. Los bancos de $\mathrm{Ma}$ lasia no dependen de financiación extranjera al por mayor para financiar las operaciones locales.

La promoción de la inclusión financiera es un objetivo obligatorio para el BNM, como indica la Ley del Banco Central de 2009. Se han hecho avances sustanciales para llegar a los más necesitados, por ejemplo, a través del desarrollo de las microfinanzas y de la educación y la protección de los consumidores. El desarrollo de las finanzas islámicas también contribuye a la inclusión financiera. $\mathrm{El}$ principal desafío es lograr un equilibrio entre las intervenciones orientadas al de mercado para avanzar en su agenda de desarrollo y crear incentivos basados en el mercado para la innovación sostenible y la sana competencia en los pagos al por menor y la banca.

Elaborado por Alexandros Mourmouras y el equipo país del FMI en Malasia.

29. La composición del crédito (a las empresas frente al de los hogares) es importante para el crecimiento. Siguiendo el enfoque de Beck et al. (2009) y Ángeles (2015), y con base en una submuestra de 30-34 países con datos disponibles sobre composición del crédito, el análisis 
indica que el crédito a las empresas tiende a tener un impacto mayor de crecimiento que el crédito a los hogares. El crédito a las empresas elimina las restricciones de financiamiento, lo que lleva a más inversión y crecimiento. En cambio, es posible que el crédito a los hogares resulte en un menor ahorro y por tanto en un menor crecimiento. Por lo general, el crédito a los hogares es mayor en países donde los sistemas financieros basados en el mercado son más grandes, la sociedad es más urbana y el sector manufacturero es más pequeño, es decir, el crédito a los hogares tiende a tener mayor participación en las EA. De hecho, en esta muestra relativamente pequeña de países, la proporción del crédito a las empresas en los ME tiende a ser mayor que en las EA.

30. Los beneficios del desarrollo de las instituciones financieras son mayores a niveles de ingreso bajos y disminuyen cuando aumenta el ingreso, mientras que sucede lo contrario para los mercados (gráfica 9). Así, una secuencia apropiada sería enfatizar el desarrollo de las instituciones en las primeras etapas y dar mayor atención al desarrollo de los mercados cuando el ingreso per cápita aumenta. Conforme a la literatura, este resultado controla otros factores, como el PIB per cápita inicial, el tamaño del gobierno, la apertura comercial, la inflación y los efectos temporales.

Gráfica 9

Efecto ingreso de la profundización financiera a diferentes niveles de desarrollo

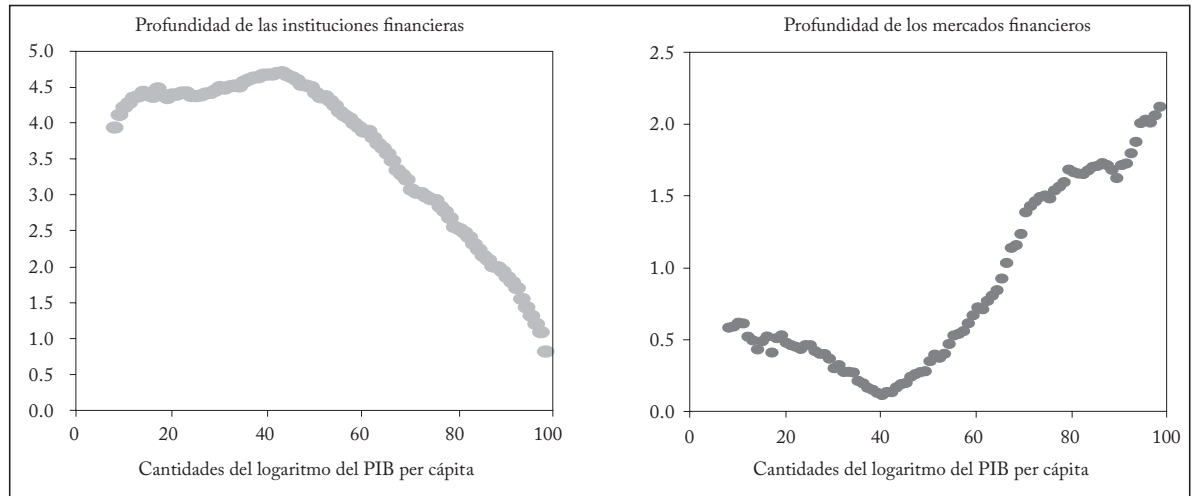

Fuente: estimaciones del personal del FMI.

31. También se exploraron los efectos de varias caracteristicas adicionales de los sistemas financieros sobre el crecimiento pero los resultados no fueron concluyentes: del impacto de la mezcla de financiación (en qué medida 
el sistema bancario dependió de fondos internos) ${ }^{10}$, de la estructura del mercado (el nivel de desarrollo de las instituciones con respecto al de los mercados), del ritmo de desarrollo financiero (la rapidez del crecimiento del índice DF o de sus subcomponentes en cada período) y del grado de integración global del sistema financiero. Los resultados no concluyentes sobre la estructura del mercado son consistentes con la literatura, que en general no encuentra que los sistemas orientados a los bancos o a los mercados tengan una ventaja intrínseca en términos de crecimiento de largo plazo. En cuanto a la integración, la falta de cobertura suficiente de los datos limita en gran medida la capacidad para detectar un efecto robusto sobre el crecimiento ${ }^{11}$.

\section{B. DESARROLLO FINANCIERO Y ESTABILIDAD}

32. La relación entre desarrollo económico y estabilidad económica también es no lineal (gráfica 10, panel izquierdo, y Anexo 2) ${ }^{12}$. Este resultado concuerda con los de estudios recientes ${ }^{13}$. El desarrollo financiero reduce inicialmente la volatilidad del crecimiento, pues permite ampliar las oportunidades para el manejo efectivo del riesgo y de la diversificación. Después de cierto punto, la volatilidad empieza a aumentar de nuevo. Curiosamente, el "punto de inflexión" de la curva de volatilidad del crecimiento del PIB está muy cerca al de la curva de crecimiento del PIB de la sección anterior. Esto sugiere que existe un rango amplio de niveles de desarrollo financiero que promueven el crecimiento económico y la estabilidad económica.

33. Los riesgos de la estabilidad financiera aumentan con la profundidad institución financiera (PIF). Para los fines de este estudio, la estabilidad financiera se aproxima por el puntaje $z$, que mide la cantidad de amortiguadores del sistema bancario tiene para protegerse de los choques de ingresos. Una puntaje de $z$ más bajo significa una menor distancia a estrés, es decir, mayores riesgos de estabilidad financiera. Como se ilustra en la gráfica 10 (panel derecho), con el aumento de

10 Este se aproximó por la relación préstamos a depósitos. Este resultado concuerda con el de la literatura sobre Europa Central y Oriental posterior a la crisis financiera de 2008, la cual muestra que los bancos que más dependían de depósitos domésticos como fuente de financiación también fueron más resistentes durante la crisis; por ejemplo, Kamil y Rai (2010). El presente artículo analiza una muestra mucho más amplia en términos de países y periodos cubiertos.

${ }^{11}$ Ver, por ejemplo, Beck y Levine (2004).

12 Para más detalles sobre el procedimiento de estimación y los resultados, ver el anexo 2, cuadro 2.

${ }_{13}$ Dabla y Srivisal (2013), en particular, analizan la relación crédito privado a PIB y volatilidad macroeconómica, y encuentran una relación no lineal similar., 
la profundidad de las instituciones financieras, los amortiguadores tienden a disminuir, si lo demás se mantiene igual.

Gráfica 10

Impacto del desarrollo financiero sobre la volatilidad del crecimiento y la estabilidad financiera

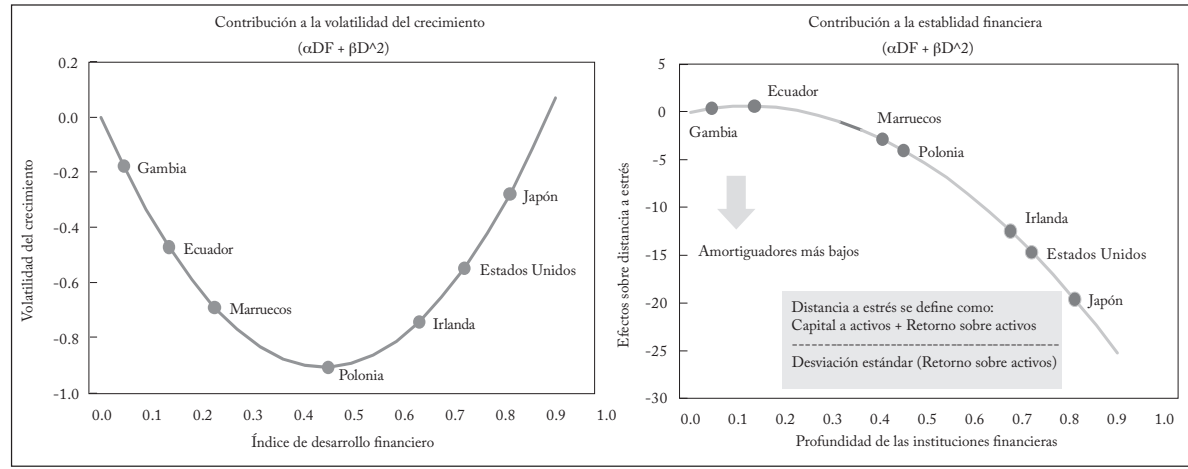

Fuente: estimaciones del personal del FMI.

34. Un ritmo más rápido de profundización financiera significa un mayor riesgo de crisis e inestabilidad macroeconómica, si todo lo demás es constante (gráfica 11). Un examen de la relación entre el ritmo de la profundización financiera y el crecimiento económico arrojó resultados no concluyentes. Pero la relación entre el ritmo de la profundización financiera en las instituciones y la volatilidad del crecimiento del PIB y la inflación es significativa y positiva. En una dirección similar, la inestabilidad financiera también aumenta con el ritmo de la profundización. Una razón plausible es que un crecimiento más rápido de las instituciones esté acompañado de una mayor toma de riesgos y un alto apalancamiento, en particular cuando el sistema financiero está mal regulado y supervisado. Cabe señalar que esta relación se mantiene para las instituciones financieras y los mercados no financieros ${ }^{14}$.

35. Con respecto a la presencia de bancos extranjeros, la evidencia preliminar sugiere que el desarrollo financiero no requiere la entrada de bancos extranjeros, mientras que su presencia no coincide necesariamente con la inestabilidad financiera. La entrada de bancos extranjeros en los sistemas financieros locales puede ser una opción práctica para que algunos países impulsen el desarrollo financiero en las primeras etapas, sobre todo cuando el tamaño del mercado interno es limitado.

${ }^{14}$ Este resultado es consistente con el de Loayza y Ranciere (2006), quienes encontraron que aunque la profundización financiera tiene un impacto positivo sobre el crecimiento, el crecimiento del crédito (cambios en la relación crédito a PIB) es uno de los predictores más confiables de las crisis financieras. 
Esa entrada puede ayudar a que los sistemas financieros locales se beneficien de economías de escala y mejoren la eficiencia a través de la mayor competencia y la innovación. Al mismo tiempo, la entrada de bancos extranjeros puede plantear retos de supervisión y aumentar la vulnerabilidad de los países a factores externos, socavando así la estabilidad financiera. Sin embargo, el panorama general que resulta de una revisión preliminar de los datos indica que los países pueden desarrollar sus sistemas financieros sin la entrada de bancos extranjeros. Y también que su presencia no necesariamente los hace más vulnerables a crisis. La gráfica 12 representa el índice promedio DF contra la participación de los activos de bancos extranjeros en los sistemas financieros domésticos en 2006-2010 (los años para los que se dispone de datos), e indica en color oscuro los países que experimentaron una crisis bancaria en este período. Sugiere que la participación extranjera en el sector bancario no tiene una relación clara bien sea con el nivel general del índice DF o con la probabilidad de crisis $^{15}$.

\section{TOMA DE MEDIDAS: ¿HAY UN TRADEOFF CRECIMIENTO-ESTABILIDAD?}

36. Combinando las piezas de evidencia empirica surge una imagen de los beneficios y riesgos cuando el desarrollo financiero pasa de bajo a alto (gráfica 13). En las primeras etapas del desarrollo financiero, el crecimiento y la estabilidad macroeconómica son reforzados por el mayor desarrollo financiero, aunque un sistema bancario más activo (y menos reprimido) empezará a reducir las reservas de capital y a estar sujeto a una mayor volatilidad de los ingresos (Región 1). En general, los riesgos se contienen y los beneficios son grandes. La Región 1 corresponde a una etapa "benevolente" del DF, donde hoy se encuentra la mayoría de los ME. Más allá de cierto nivel, el mayor desarrollo financiero aumentará la volatilidad económica, aunque los efectos de crecimiento siguen siendo positivos y las reservas siguen disminuyendo. Esto corresponde a la región de tradeoff (Región 2), donde hoy se encuentran algunos ME y EA. Por último, más allá de algún punto, el desarrollo financiero lleva a un menor crecimiento y una mayor volatilidad (Región 3), una indicación de que hay demasiadas finanzas.

37. A la luz del tradeoff beneficios-riesgos, una pregunta clave es si es posible empujar las fronteras de las regiones "benevolentes". Como ilustra el recuadro 4, las tres regiones también están relacionadas

${ }^{15} \mathrm{La}$ falta de vínculos entre propiedad extranjera del sector bancario y probabilidad de crisis se puede explicar por el hecho de que los países con gran presencia de bancos extranjeros no experimentaron crisis financieras debido a rápidas acciones de política que estabilizaron el crédito. 
Gráfica 11

Ritmo de la profundidad financiera vs. estabilidad económica y financiera

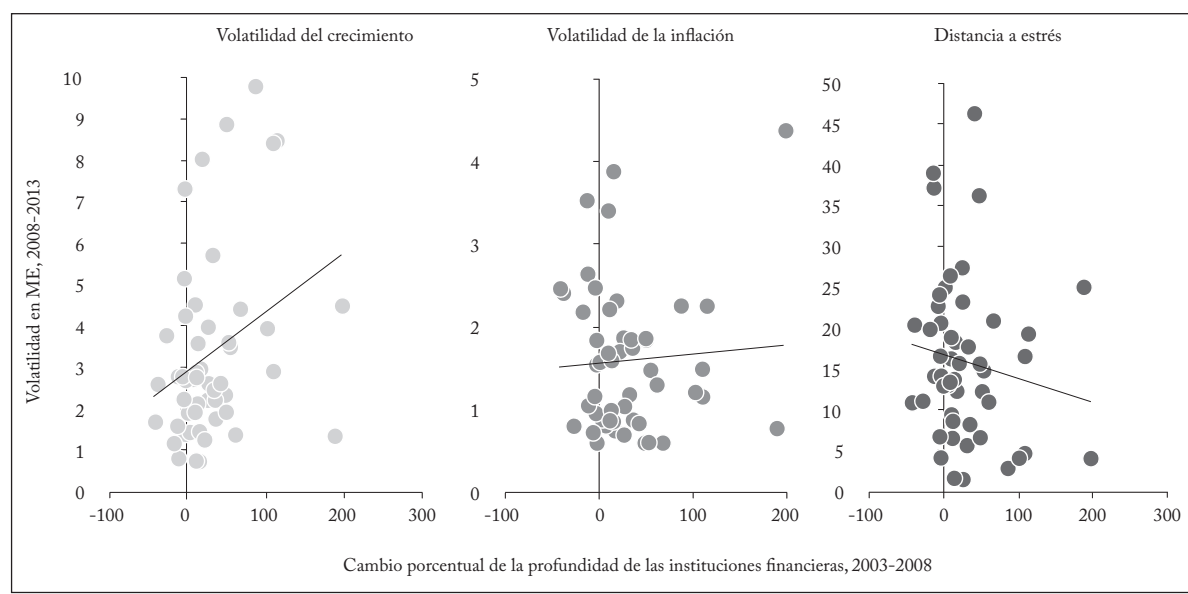

Fuente: estimaciones del personal del FMI.

con los costos sociales y los beneficios marginales del aumento del desarrollo financiero. Se puede pensar en un nivel "social óptimo" del DF como el punto en el que estos costos y beneficios marginales se igualan (DF* en el recuadro 4, gráfica 1 ). Aunque la ubicación exacta del óptimo social varía según el país -lo que depende esencialmente de las preferencias normativas de las autoridades de política acerca del crecimiento frente a la estabilidad macroeconómica y financiera-, se sitúa necesariamente en algún lugar de la Región 2, donde los costos

Gráfica 12

Participación de los bancos extranjeros

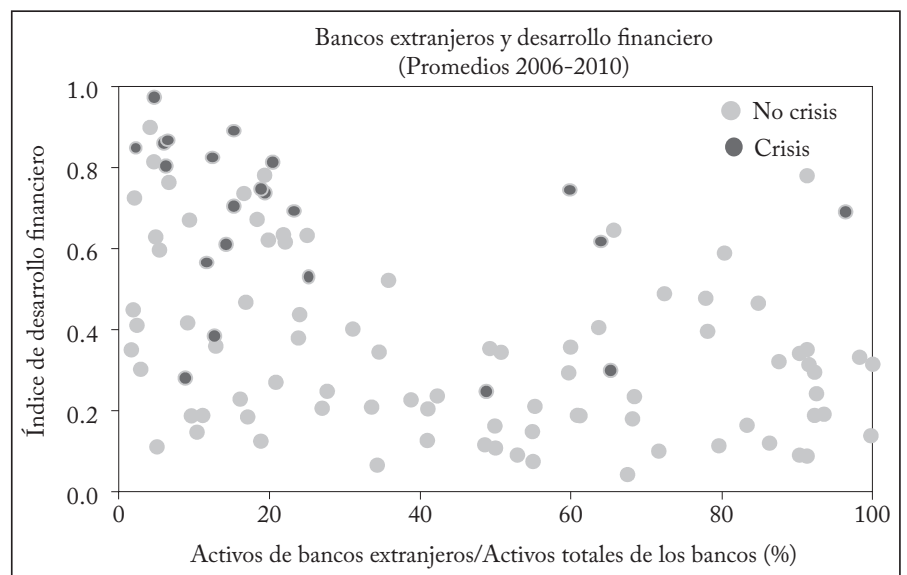

Fuente: World Bank Global Financial Development Database, cálculos del personal del FMI. 
y beneficios marginales son positivos. ¿Las fronteras entre regiones pueden ser empujadas a través de acciones de política? Por ejemplo, ¿hay circunstancias en las que los países de la Región 1 (la "región benevolente") pueden permanecer en esa región incluso con mayores niveles de desarrollo financiero? O ¿ ¿los países de la Región 3 pueden pasar a las regiones 2 o 1 sin reducir necesariamente su desarrollo financiero? En otras palabras, ¿hay medidas de política que pueden permitir que los países alcancen su óptimo social a un nivel más alto de DF? La siguiente sección busca arrojar luz sobre esta cuestión.

Gráfica 13

Tradeoff crecimiento-estabilidad

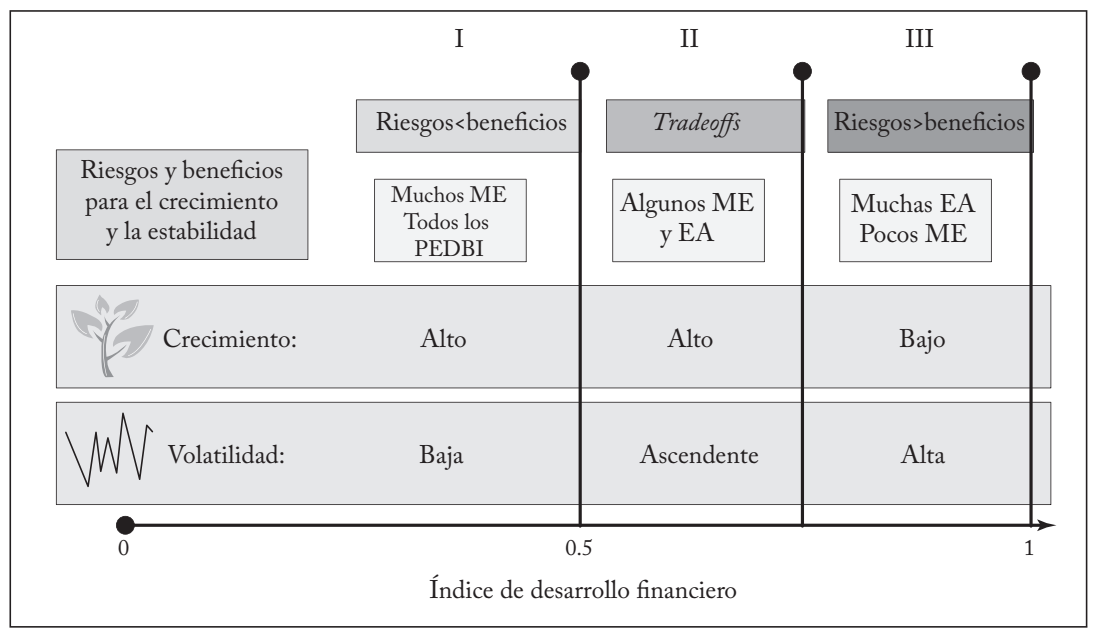

Nota: $\mathrm{EA}$ = economías avanzadas, $\mathrm{ME}=$ mercados emergentes, $\mathrm{PEDBI}=$ países en desarrollo de bajos ingresos.

Fuente: estimaciones del personal del FMI.

\section{RECUADRO 4 \\ BENEFICIOS Y COSTOS DEL DESARROLLO FINANCIERO MARGINAL SOCIAL ${ }^{16}$}

El análisis empírico que se describe en la sección C muestra que el desarrollo financiero tiene efectos no lineales sobre el crecimiento económico y la estabilidad. Una manera útil de resumir las implicaciones de estos resultados para la política económica es definir primero el efecto marginal en el crecimiento y los beneficios sociales marginales del desarrollo financiero; luego agrupar los impactos marginales sobre la estabilidad -macroeconómica y financiera- en costos sociales marginales del desarrollo financiero. Se puede entonces definir un nivel "socialmente óptimo" del desarrollo financiero como aquel donde se igualan los costos y beneficios marginales.

${ }^{16}$ Los autores agradecen a José Viñals por la presentación de este análisis. 
Esto se ilustra en la gráfica siguiente, donde se muestra el nivel de desarrollo financiero en el eje horizontal, y los costos y beneficios sociales en el eje vertical. La línea $M B F$ corresponde al beneficio social marginal de las finanzas, y es igual a la pendiente de la relación en forma de campana entre finanzas y crecimiento de la gráfica 7 . Los beneficios marginales son inicialmente positivos pero decrecientes, hasta llegar al punto a la derecha del cual son negativos. Los costos sociales marginales de las finanzas son representados por la línea $M C F$, que inicialmente es negativa pero creciente, luego positiva y finalmente sobrepasa a los beneficios marginales. La construcción de $M C F$ no es tan sencilla como la de $M B F$, pues implica agregar más de tres efectos: sobre el producto, sobre la volatilidad de la inflación y sobre la estabilidad financiera. Así, el diseñador de políticas debe hacer un juicio normativo que pondere los tres objetivos de estabilidad desde el punto de vista social. También implica ponderar los costos con respecto a los beneficios. Es decir, el diseñador de políticas debe decidir, por ejemplo, cuántos puntos porcentuales de aumento de la volatilidad valen la pena socialmente en términos de un punto porcentual de crecimiento adicional. Una representación plausible es que los costos marginales negativos de la reducción de la volatilidad macroeconómica sobrepasen a los costos marginales positivos (constantes) provenientes de la reducción de los amortiguadores. Por lo tanto, en la gráfica $M C F$ es inicialmente negativa, pero aumenta con el desarrollo financiero.

A partir de este análisis se pueden identificar tres regiones separadas de desarrollo financiero. En las primeras etapas, Región 1, hay claros beneficios de la búsqueda de desarrollo financiero, pues los beneficios marginales (crecimiento) son positivos y los costos (estabilidad) son negativos. En la Región 2, los costos marginales se tornan positivos, pero un mayor desarrollo financiero seguirá teniendo un beneficio social neto hasta $D F^{*}$ cuando los beneficios marginales son iguales a los costos marginales. En $D F^{*}$ se alcanza el "óptimo social" (OS*). Por último, la Región 3 representa un área de "demasiadas finanzas" donde hay costos claros de un mayor desarrollo financiero; los beneficios marginales son negativos y los costos son positivos ${ }^{17}$. La sociedad entonces se beneficiaría claramente de una contracción de las finanzas, saliendo de la Región 3.

En el área de la Región 2 a la derecha de $D F^{*}$, el freno del desarrollo financiero moviéndose hacia la izquierda mejora el bienestar social. Sin embargo, la localización exacta del óptimo social dependerá necesariamente de la ponderación normativa de los costos relativos a la estabilidad financiera. En cambio, en la Región 3 el nivel de desarrollo financiero es subóptimo, independientemente de la ponderación normativa del diseñador de políticas.

${ }^{17}$ Usando los resultados de las estimaciones, la frontera entre las regiones 2 y 3 se puede establecer a un nivel de 0,7 , donde el impacto marginal de crecimiento del DF se vuelve estadísticamente menor que 0 a un nivel del $95 \%$. En cuanto a la frontera entre las regiones 1 y 2 , no es claro dónde se vuelven positivo los costos marginales totales, pues esto involucra una ponderación normativa de los costos marginales de la volatilidad de la inflación, que llegan a ser positivos cerca de 0,4 ; de la volatilidad de producto, que llegan a ser positivos a un nivel de DF de cerca de 0,5 , y de estabilidad financiera, que son positivos a todos los niveles de DF. Para fines de ilustración, la frontera entre las regiones 1 y 2 aquí se fija a un nivel de DF de 0,4. 
La gráfica se dibujó en forma "estática”, es decir, suponiendo que las curvas $M B F$ y $M C F$ no se mueven y, por tanto, que la ubicación de las regiones y el óptimo social también son estáticos. Sin embargo, los resultados también sugieren que las acciones seleccionadas en el entorno favorable, y más específicamente en los principios regulatorios, puede desplazar potencialmente ambas curvas a la derecha (p. ej., de OS $^{*}$ a OS $\left.^{* *}\right)$, y con ello alterar el tradeoff crecimiento-estabilidad, así como el óptimo social. Por tanto, las mejoras regulatorias e institucionales pueden servir para ampliar la benevolente Región 1 o la Región 2, o para reducir la Región 3, mitigando las consecuencias negativas de crecimiento y estabilidad de los niveles más altos de desarrollo financiero.

Por último, la gráfica se refiere a los beneficios y costos sociales del desarrollo financiero. En ciertos casos y a niveles de finanzas muy altos, los beneficios sociales de reducir el desarrollo financiero son bastante sobrepasados por los beneficios privados de las finanzas. En este caso, la Región 3 es válida y el como objetivo de las medidas regulatorias debería ser inducir al sector privado a reducir el desarrollo financiero a un nivel más consistente con los beneficios sociales.

Beneficios y costos sociales marginales del desarrollo financiero

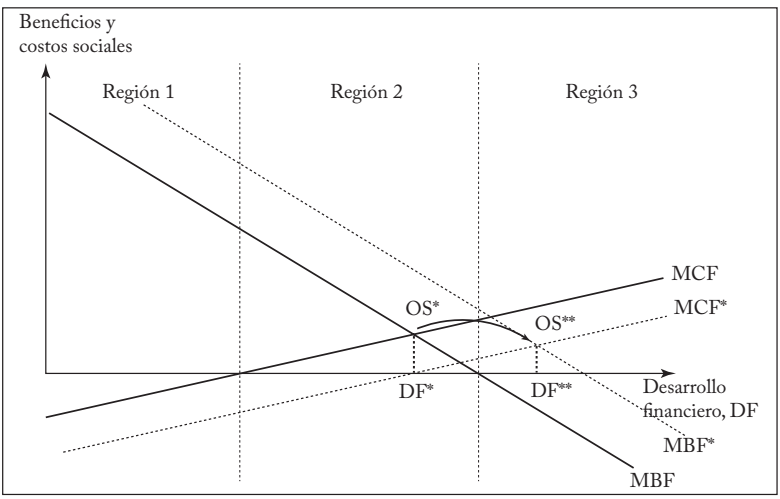

Fuente: personal del FMI

\section{CREAR UN ENTORNO FAVORABLE}

38. Esta sección examina los factores que pueden ayudar a que los paises mantengan un mayor nivel de desarrollo financiero, mientras que mitigan los riesgos de estabilidad macroeconómica y financiera.

39. Un primer paso es probar el papel del entorno institucional ${ }^{18}$. Como era de esperar, unas instituciones fuertes - mejor protección de los

${ }^{18}$ Dada la importancia de la calidad institucional, puede parecer natural incluirla en el índice integral DF. ¿Por qué no se incluye? El enfoque de este trabajo es construir un índice que refleje las condiciones del sistema financiero en sí mis- 
derechos de propiedad, derechos de los acreedores e información, y mayor calidad de la regulación y del Estado de derecho- están asociadas positivamente con un mayor desarrollo financiero, en el índice general DF y con respecto a instituciones y mercados (gráfica 14) ${ }^{19}$. Hay una excepción: como también se podía esperar, las mejoras de los derechos de los acreedores y de la información tienden a tener un efecto medible únicamente en las instituciones.

\section{Gráfica 14}

Papel de la regulación en el desarrollo financiero

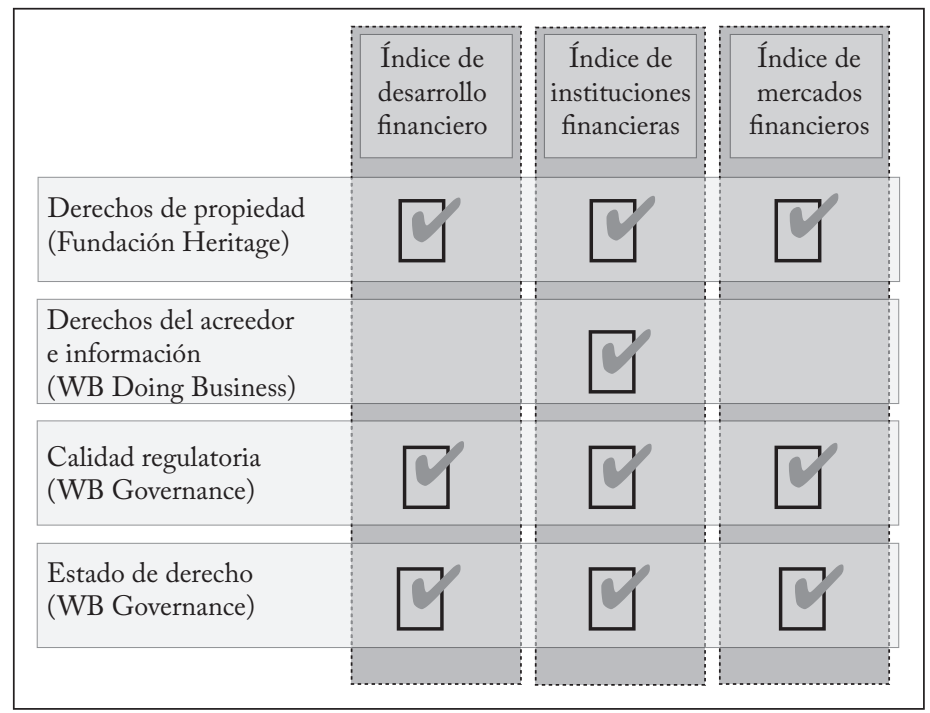

Fuente: estimaciones del personal del FMI.

40. Profundizando se encuentra una fuerte correlación positiva entre desarrollo financiero y calidad del marco regulatorio. Esta se aproxima aquí por la calificación total de los países en el cumplimiento de los Principios Básicos de Basilea (PBB), los Principios Básicos de Seguros (PBS) y los principios de la Organización Internacional de Comisiones de Valores (IOSCO) (gráfica 14).

mo. Obviamente, la calidad institucional afecta el DF, pero también influye en otros sectores de la economía. Además, dejarla por fuera del índice DF tiene el beneficio adicional de que es posible probar su relevancia y su interacción con el DF para afectar el crecimiento y la estabilidad.

${ }^{19}$ Estos resultados son consistentes con los de un gran conjunto de trabajos anteriores. Por ejemplo, un documento conjunto del FMI, el BM, el BERD y la OCDE (2013) destacó el papel de los marcos legales robustos -en particular con respecto al cumplimiento de las garantías- en el desarrollo de los mercados de bonos en moneda local. 
41. Profundizando aún más se encuentra que en términos de principios regulatorios hay muy poco tradeoff entre desarrollo financiero y estabilidad financiera. ¿Hay algunas regulaciones eficaces para ayudar a salvaguardar la estabilidad financiera pero que obstaculizan el desarrollo financiero? El análisis que se resume en la gráfica 15 sigue la metodología de la Junta Revisora del FMI del Programa de Evaluación del Sector Financiero (FMI, 2014d). Estos principios se agrupan en principios de banca, seguros y valores. En el FMI (2014d) se identificó que algunos de ellos estaban asociados significativamente con la estabilidad financiera, en el sentido de que reducen la probabilidad de experimentar una crisis bancaria. En la gráfica 15 la línea sólida rodea estos principios. Usando la misma metodología se pueden identificar los principios asociados positivamente con el desarrollo financiero, rodeados por la línea punteada. Es llamativo que para los dos conjuntos de principios, el conjunto que importa para la estabilidad financiera y el que importa para el desarrollo financiero coinciden ampliamente. De manera más específica, se encontró que 25 de los 93 principios regulatorios (PBB, PBS e IOS$\mathrm{CO}$ ) fueron fundamentales para la estabilidad financiera, y que 23 de ellos fueron críticos para el desarrollo financiero. En términos generales, estos principios clave captan: 1) la capacidad de los reguladores para establecer y exigir ajustes de capital, provisiones de cartera perdida y remuneración de los empleados; 2) las definiciones de la regulación, como las de capital, préstamos morosos y cartera perdida, y 3) información y revelación financiera ${ }^{20}$. Esto no significa que los principios restantes no sean importantes. Quienes elaboran las normas tienen en mente otras consideraciones y objetivos relevantes (como la seguridad y la solidez, y la protección de los asegurados) y los principios restantes se consideran útiles desde la perspectiva de los emisores de normas, pero no parecen necesariamente "críticos" desde la perspectiva de la estabilidad financiera y del desarrollo financiero ${ }^{21}$.

20 Más concretamente, (de los 93) los 25 principios siguientes se encontraron críticos para la estabilidad financiera en el análisis econométrico del FMI (2014d): los principios PBB 2, 3, 5, 12, 13, 15, 17, 19, 22, 25,27 y 28; los PBS 5, 8, 16, 17,19 , y 25 ; y los objetivos IOSCO $1,5,14,15,16,18$ y 19 . De estos 25 principios, solo el PBB 15 (riesgo operativo) y el IOSCO 15 (asistencia a reguladores extranjeros) no resultaron críticos para el desarrollo financiero.

${ }^{21}$ Cabe recordar que en este análisis la estabilidad financiera se define como una baja probabilidad de sufrir una crisis bancaria, un evento de cola. Es posible que haya otros aspectos de estabilidad financiera para los cuales otras normas regulatorias tienen un efecto mensurable. 
Gráfica 15

Regulación

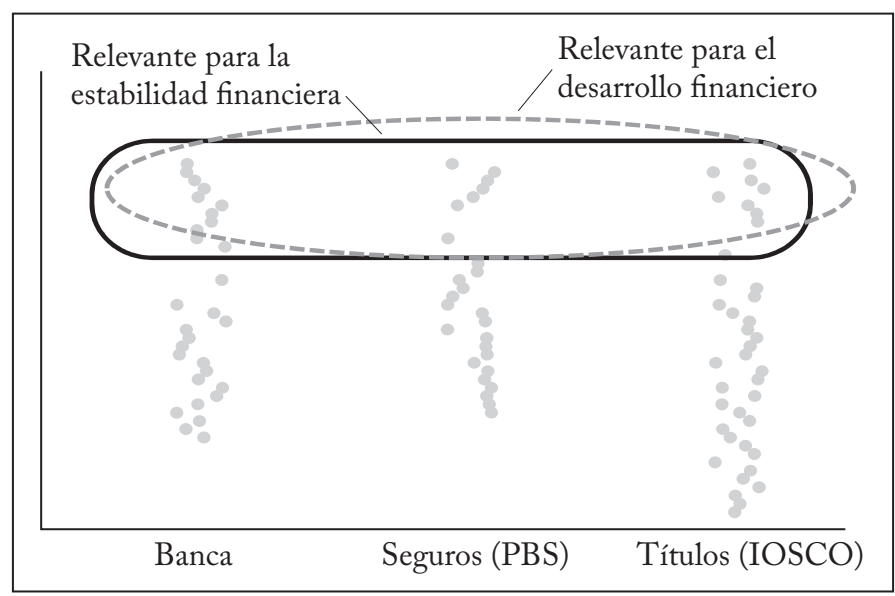

Nota: PBS = Programa de Comparación Internacional; IOSCO = Organización Internacional de Comisiones de Valores.

Fuente: estimaciones del personal del FMI.

42. Estos resultados implican que muchos paises pueden tomar medidas concretas en el frente regulatorio para promover simultáneamente el desarrollo financiero y la estabilidad. Dado que un canal a través del cual operan las "demasiadas finanzas" es la propensión de los sistemas financieros más grandes a generar inestabilidad financiera, los resultados anteriores sugieren que la aplicación efectiva de los principios clave de la regulación puede ayudar a desplazar a la derecha las fronteras de las tres regiones de la gráfica 13 , del recuadro 4 y de la gráfica 1 , es decir, aumentar el desarrollo financiero sin incurrir en costos adicionales en términos de menor crecimiento o mayor volatilidad ${ }^{22}$.

\section{CONCLUSIÓN}

43. La evidencia que se presenta en este trabajo muestra que la mayoria de los $M E$ se sitúa aún en la región relativamente segura y promotora del crecimiento del desarrollo financiero y tienen margen para un mayor desarrollo. La mayoría de los ME puede cosechar los beneficios de un mayor desarrollo financiero, es decir lograr mayor crecimiento y estabilidad financiera, y reducir la volatilidad macroeconómica. Pero es

${ }^{22}$ Sería ideal probar directamente esta hipótesis, incluyendo en las regresiones de crecimiento interacciones con variables regulatorias para evaluar si el punto de inflexión no gira a la izquierda cuando la calidad regulatoria mejora. Sin embargo, no hay suficiente variación en el tiempo de las variables regulatorias para que sean captadas en una regresión de crecimiento de largo plazo. 
necesario subrayar que los riesgos de estabilidad financiera aún están presentes a bajos niveles de desarrollo financiero y, por tanto, que las autoridades deben garantizar que se mantengan suficientes reservas para reducir los riesgos de una crisis financiera.

44. El análisis muestra que el desarrollo financiero implica tradeoffs, pero estos se pueden compensar construyendo instituciones fuertes y un entorno regulador/supervisor sólido. El análisis revela evidencia de "demasiadas finanzas" en los últimos años, es decir, más allá de cierto nivel de desarrollo financiero los beneficios del crecimiento comienzan a disminuir y los costos en términos de volatilidad económica y financiera comienzan a aumentar. Después de la crisis financiera mundial de 2008, a nivel mundial se propusieron cambios radicales en los marcos regulatorios y se han ejecutado sustancialmente. Estas reformas buscan hacer más seguros los sistemas financieros y potencialmente pueden ampliar las fronteras de las regiones 1 y 2, maximizando los beneficios del desarrollo financiero al tiempo que se minimizan los riesgos. De hecho, uno de los efectos de las reformas regulatorias globales ha sido el desapalancamiento en la $\mathrm{EA}$, lo que confirma implícitamente que había "demasiadas finanzas”. Una ejecución completa de estas reformas regulatorias sería un buen augurio para las perspectivas de crecimiento y estabilidad de todos los países.

45. Este estudio tiene claras lecciones para los ME. Primera, el desarrollo financiero es multifacético y se debe medir observando muchos indicadores. Segunda, el desarrollo financiero se puede promover estableciendo un fuerte entorno regulatorio y de supervisión de los negocios. De los 93 principios regulatorios, los principios críticos que importan para el desarrollo económico y la estabilidad financiera son en esencial los mismos. Esto significa que una regulación mejor -no más regulación- es lo que promueve la estabilidad financiera y el desarrollo. Tercera, puesto que el efecto de debilitamiento del crecimiento a los niveles más altos de desarrollo financiero proviene de la profundización financiera, el aumento del acceso o la eficiencia a cualquier nivel de desarrollo financiero sería benéfico. Cuarta, para mitigar riesgos económicos y de estabilidad financiera, así como para reducir la probabilidad de una crisis, se debe evitar un ritmo demasiado rápido de desarrollo financiero. Por último, no hay "una receta única para todos” en términos de la secuencia del desarrollo de los sistemas financieros, pero con el tiempo los beneficios relativos de las instituciones disminuyen y los de los mercados aumentan. 


\section{REFERENCIAS BIBLIOGRÁFICAS}

1. Aizenman, J.; Y. Jinjarak y D. Park. "Financial development and output growth in developing Asia and Latin America: A comparative sectoral analysis", NBER working paper 20917, Cambridge, Mass., 2015.

2. Angeles, L. "Credit expansion and the real economy", Applied Economics Letters 1-9, 2015.

3. Arcand, J.-L.; E. Berkes y U. Panizza. "Too much finance?" IMF working paper 12/161, Washington, D. C., 2012.

4. Bagehot, W. Lombard Street, Homewood, Ill., Richard D. Irwin, 1873.

5. Barajas, A.; R. Chami y S. R. Yousefi. "The finance and growth nexus re-examined: Do all countries benefit equally?", IMF working paper 13/130, Washington, D. C., 2013.

6. Beck, T.; B. Büyükkarabacak et al. "Stock markets, banks and growth: Panel evidence", Journal of Banking and Finance 28, 3, 2004, pp. 423-442.

7. Beck, T.; B. Büyükkarabacak et al. "Who gets the credit? And does it matter? Enterprise vs. household credit across countries", Center discussion paper, Tilburg University, Germany, 2009.

8. Bernanke, B.; M. Gertler y S. Gilchrist. "The financial accelerator in a quantitative business cycle framework", NBER working paper 6455, Cambridge, Mass., 1999.

9. Cecchetti, S. G. y E. Kharroubi. "Why does financial sector growth crowd out real economic growth?”, BIS working paper 490, Basilea, 2015.

10. Čihák, M.; A. Demirgüç-K. et al. "Benchmarking financial development around the world", World Bank policy research working paper 6175, Washington, D. C., 2012.

11. Dabla-N., E. y N. Srivisal. "Revisiting the link between finance and macroeconomic volatility", IMF working paper 13/29, Washington, D. C., 2013.

12. Dabla-N., E.; S. Guo et al. "The new normal: A sector-level perspective on growth and productivity trends in advanced economies", IMF staff discussion note, Washington, D. C., 2015.

13. De Gregorio, J. y P. Guidotti. "Financial development and economic growth", World Development 23, 3, 1995, pp. 433-448.

14. De la Torre, A.; A. Ize y S. Schmuckler. Financial Development in Latin America and the Caribbean, Washington, D. C., World Bank, 2012.

15. Eugster, J. "Nonlinear marginal effects of finance on growth", no publicado, IMF, Washington, D. C., 2014.

16. Gallego, F. y N. Loayza. "Financial structure in Chile: Macroeconomic developments and microeconomic effects", working paper 75, Banco Central de Chile, Santiago, 2000.

17. Gennaioli, N.; A. Shleifer y R. Vishny. "Neglected risks, financial innovation, and financial fragility", Journal of Financial Economics 104, 3, 2012, pp. 452-468.

18. IMF. "Shadow banking around the globe: How large and how risky?", Global Financial Stability Report, Washington, D. C., octubre de 2014a. 
19. IMF. "How do changes in the investor base and financial deepening affect emerging market economies?", Global Financial Stability Report, Washington, D. C., abril de 2014b.

20. IMF. Toward new horizons: Arab economic transformation amid political transitions, Washington, D. C., 2014c.

21. IMF. Review of the financial sector assessment program: Further adaptation to the post crisis era, Washington, D. C., 2014d.

22. IMF. World Economic Outlook, Washington, D. C., octubre de 2014e.

23. IMF, World Bank, European Bank for Reconstruction and Development, and OECD. "Local currency bond markets - A diagnostic framework", Washington, D. C., 2013.

24. Kamil, H. y K. Rai. "The global credit crunch and foreign banks" lending to EMs: Why did Latin America fare better?", working paper 10/102, IMF, Washington, D. C., 2010.

25. Khan, M.; A. Senhadji y B. Smith. "Inflation and financial depth", working paper 01/44, IMF, Washington, D. C., 2001.

26. King, R. y R. Levine. "Finance and growth: Schumpeter might be right", Quarterly Journal of Economics 108, 3, 1993, pp. 717-737.

27. Laeven, L. y F. Valencia. "Systemic banking crises database: An update”, IMF working paper 12/163, Washington, D. C., 2012.

28. Levine, R. "Finance and growth: Theory and evidence", Ph. Aghion y S. Durlauf, eds., Handbook of economic growth, Nueva York, Elsevier, 2005, pp. 865-934.

29. Levine, R.; N. Loayza y T. Beck. "Finance and the sources of growth", Journal of Financial Economics 58, 1-2, 2000, pp. 261-300.

30. Loayza, N. y R. Ranciere. "Financial development, financial fragility, and growth", Journal of Money, Credit and Banking 38, 4, 2006, pp. 1051-1076.

31. McKinnon, R. Money and capital in economic development, Washington, D. C., Brookings Institution, 1973.

32. Nili, M. y M. Rastad. "Addressing the growth failure of the oil economies: The role of financial development", Quarterly Journal of Economics and Finance 46, 5, 2007, pp. 726-740.

33. Philippon, T. y A. Reshef. "Wages and human capital in the U.S. finance industry: 1909-2006", Quarterly Journal of Economics 127, 4, 2012, pp. 1551-1169.

34. Philippon, T. y A. Reshef. "An international look at the growth of modern finance", Journal of Economic Perspectives 27, 2, 2013, pp. 73-96.

35. Rajan, R. "Has financial development made the world riskier?", NBER working paper 11728, Cambridge, Mass., 2005.

36. Robinson, J. "The generalization of the General Theory", The rate of interest and other essays, Londres, Macmillan, 1952.

37. Rousseau, P. y P. Wachtel. "What is happening to the impact of financial deepening on economic growth?", Economic Inquiry 49, 1, 2011, pp. 276-288.

38. Shaw, E. Financial deepening in economic development, Nueva York, Oxford University Press, 1973.

39. Wolf, M. "Why dealing with the huge debt overhang is so hard", Financial Times, 27 de enero de 2009. 
40. World Bank. Global financial development report 2014 - Financial inclusion, Washington, D. C., 2014. 